\title{
Development
}

\section{Carrier of Wingless (Cow) Regulation of Drosophila Neuromuscular Junction Development}

\author{
DDanielle L. Kopke, ${ }^{1}$ Shannon N. Leahy, ${ }^{1}$ DDominic J. Vita, ${ }^{1}$ Sofia C. Lima, ${ }^{1}$ Zachary L. Newman, ${ }^{2}$ and \\ (1) Kendal Broadie ${ }^{1}$
}

https://doi.org/10.1523/ENEURO.0285-19.2020

${ }^{1}$ Department of Biological Sciences, Kennedy Center for Research on Human Development, Vanderbilt University, Nashville, Tennessee 37235 and ${ }^{2}$ Department of Molecular and Cell Biology, University of California, Berkeley, Berkeley, California 94720

\begin{abstract}
The first Wnt signaling ligand discovered, Drosophila Wingless [Wg (Wnt1 in mammals)], plays critical roles in neuromuscular junction (NMJ) development, regulating synaptic architecture, and function. Heparan sulfate proteoglycans (HSPGs), consisting of a core protein with heparan sulfate (HS) glycosaminoglycan (GAG) chains, bind to $\mathrm{Wg}$ ligands to control both extracellular distribution and intercellular signaling function. Drosophila HSPGs previously shown to regulate Wg trans-synaptic signaling at the NMJ include the glypican Dally-like protein (Dlp) and perlecan Terribly Reduced Optic Lobes (Trol). Here, we investigate synaptogenic functions of the most recently described Drosophila HSPG, secreted Carrier of Wingless (Cow), which directly binds Wg in the extracellular space. At the glutamatergic NMJ, we find that Cow secreted from the presynaptic motor neuron acts to limit synaptic architecture and neurotransmission strength. In cow null mutants, we find increased synaptic bouton number and elevated excitatory current amplitudes, phenocopying presynaptic Wg overexpression. We show cow null mutants exhibit an increased number of glutamatergic synapses and increased synaptic vesicle fusion frequency based both on GCaMP imaging and electrophysiology recording. We find that membranetethered Wg prevents cow null defects in NMJ development, indicating that Cow mediates secreted Wg signaling. It was shown previously that the secreted Wg deacylase Notum restricts Wg signaling at the NMJ, and we show here that Cow and Notum work through the same pathway to limit synaptic development. We conclude Cow acts cooperatively with Notum to coordinate neuromuscular synapse structural and functional differentiation via negative regulation of $\mathrm{Wg}$ trans-synaptic signaling within the extracellular synaptomatrix.
\end{abstract}

Key words: Drosophila; HSPG; neuromuscular junction; synaptomatrix

\section{Significance Statement}

Wnt intercellular signaling is disrupted in numerous devastating neurologic disorders, including Alzheimer's disease. Therefore, an understanding of Wnt signaling regulation is important for the design and implementation of targeted treatments. As a disease model, the Drosophila glutamatergic neuromuscular junction (NMJ) system is large, accessible, and genetically malleable, and thus well suited for discovering the molecular and cellular mechanisms of Wnt signaling regulation. Extracellular heparan sulfate proteoglycans (HSPGs) are important players as regulators of Wnt intercellular signaling. Here, we show secreted HSPG Carrier of Wingless (Cow), which directly binds to the founding Wnt-1 ligand, regulates NMJ structure and function. The mammalian homolog of Cow, Testican-2, is highly expressed in the brain. Studying this HSPG in Drosophila should inform mechanisms of Wnt regulation in human brain.

Received July 18, 2019; accepted January 27, 2020; First published February $5,2020$.

The authors declare no competing financial interests.
Author contributions: D.L.K., S.C.L., and K.B. designed research; D.L.K., S.N.L., D.J.V., and S.C.L. performed research; D.L.K., S.N.L., D.J.V., S.C.L., and Z.L.N. analyzed data; D.L.K. and K.B. wrote the paper. 


\section{Introduction}

The developing nervous system requires the coordinated action of many signaling molecules to ensure proper synapse formation and function. One key class of signals is the Wnt ligands. The first discovered Wnt, Drosophila Wingless $(\mathrm{Wg})$, is secreted from presynaptic neurons (Packard et al., 2002) and glia (Kerr et al., 2014) at the developing glutamatergic neuromuscular junction (NMJ) to bind to the Frizzled-2 (Fz2) receptor (Bhanot et al., 1996) in both anterograde and autocrine signaling. In the postsynaptic muscle, Wg binding to Fz2 activates the noncanonical Frizzled Nuclear Import (FNI) pathway, which leads to Fz2 endocytosis and cleavage of the Fz2 C terminus (Fz2-C; Mathew et al., 2005). The Fz2-C fragment is trafficked to the nucleus to control translation of synaptic mRNAs and glutamate receptors (GluRs; Speese et al., 2012). In presynaptic neurons, Wg binding to Fz2 activates a divergent canonical pathway inhibiting glycogen synthase kinase $3 \beta$ (GSK3 $\beta$ ) homolog Shaggy (Sgg) to control microtubule cytoskeletal dynamics via the microtubuleassociated protein 1B (MAP1B) homolog Futsch (Miech et al., 2008), resulting in synaptic bouton growth (Franco et al., 2004; Ataman et al., 2008). The Wg signaling ligand must be tightly regulated in the synaptic extracellular space (synaptomatrix) to ensure proper NMJ development.

One critical category of proteins regulating Wg ligand in the synaptomatrix is heparan sulfate proteoglycans (HSPGs; Kamimura and Maeda, 2017). HSPGs consist of a core protein to which heparan sulfate (HS) glycosylphosphatidylinositol (GAG) chains are covalently attached. HS GAG chains are composed of repeating disaccharide subunits expressing variable sulfation patterns (the "sulfation code"; Masu, 2016). These GAG chains bind secreted extracellular ligands to regulate intercellular signaling. There are three HSPG families: transmembrane; glycerophosphatidylinositol (GPI) anchored; and secreted. The Drosophila genome encodes only five HSPGs, with the following three known to affect NMJ development: transmembrane syndecan (Johnson et al., 2006); GPI-anchored Dally-like protein (Dlp; Johnson et al., 2006; Dani et al., 2012); and secreted perlecan (Kamimura et al., 2013). A second secreted HSPG recently characterized in Drosophila was named Carrier of Wingless (Cow; Chang and Sun, 2014). In the developing wing disk, Cow directly binds secreted $\mathrm{Wg}$ and promotes its extracellular transport in an HS-dependent manner. Cow shows a biphasic effect on Wg target genes. Removing Cow results in a $\mathrm{Wg}$ overexpression (OE) phenotype for shortrange targets, and a loss-of-function phenotype for longrange targets (Chang and Sun, 2014).

The mammalian homolog of Cow, Testican-2, is highly expressed within the developing mouse brain (Vannahme

This work was supported by National Institutes of Health Grants MH-096832 to K.B. and F31-MH-111144 to D.L.K.

Correspondence should be addressed to Kendal Broadie at kendal. broadie@vanderbilt.edu.

https://doi.org/10.1523/ENEURO.0285-19.2020

Copyright (C) 2020 Kopke et al.

This is an open-access article distributed under the terms of the Creative Commons Attribution 4.0 International license, which permits unrestricted use, distribution and reproduction in any medium provided that the original work is properly attributed. et al., 1999), and inhibits neurite extension in cultured neurons (Schnepp et al., 2005), although the mechanism of action is not known. We therefore set out to characterize Cow functions at the developing Drosophila NMJ. We use the larval NMJ model because it is large, accessible and particularly well characterized for HSPG-dependent Wg transsynaptic signaling (Sears and Broadie, 2018). Each NMJ terminal consists of a relatively stereotypical innervation pattern, with consistent axonal branching and synaptic bouton formation (Menon et al., 2013). Boutons are the functional unit of the NMJ, containing presynaptic components required for neurotransmission including glutamatecontaining synaptic vesicle (SV) pools and specialized active zone (AZ) sites for SV fusion. AZs contain Bruchpilot (Brp) scaffolds, which both cluster $\mathrm{Ca}^{2+}$ channels (Kittel et al., 2006) and tether SVs (Hallermann et al., 2010). AZs are directly apposed to GluR clusters in the postsynaptic muscle membrane (Schuster et al., 1991). This spatially precise juxtaposition is critical for high-speed and efficient synaptic communication between neuron and muscle.

In this study, we sought to test Cow functions at the NMJ, with the hypothesis that Cow should facilitate extracellular Wg transport across the synapse. Structurally, cow null mutants display overelaborated NMJs with more boutons and more synapses, phenocopying Wg overexpression. This phenotype is replicated with targeted neuronal Cow knockdown, but not muscle Cow knockdown, which is consistent with Cow secretion from the presynaptic terminal. Functionally, cow null mutants display increased synaptic transmission strength. Both electrophysiology recording and postsynaptically targeted GCaMP imaging show increased SV fusion, indicating elevated presynaptic function. Replacing native $\mathrm{Wg}$ with a membrane-tethered Wg blocks secretion (Alexandre et al., 2014). Tethered Wg has little effect on NMJ development, but when combined with the cow null suppresses the synaptic bouton increase, indicating that Cow mediates only secreted Wg signaling. It was recently shown that Notum, a secreted Wg deacylase, also restricts Wg signaling at the NMJ (Kopke et al., 2017). We show here that combining null cow and notum heterozygous mutants causes a synergistic increase in NMJ development, indicating nonallelic noncomplementation. Moreover, combining null cow and notum homozygous mutants did not cause an increase in NMJ development compared with the single nulls, indicating an interaction within the same pathway. We conclude that Cow functions via negative regulation of Wg trans-synaptic signaling.

\section{Materials and Methods}

\section{Drosophila genetics}

All Drosophila stocks were reared on standard cornmeal/agar/molasses food at $25^{\circ} \mathrm{C}$ in a $12 \mathrm{~h}$ light/dark cycling incubator. Mixed sexes were used for all experiments except the SynapGCaMP imaging (females only). The genetic background control was $w^{1118}$. The cow ${ }^{5 \Delta}$ mutant, UAS-cow-miRNA-1 (referred to as UAS-cow-RNAi) and UAS-SP-eGFP-cow (referred to as UAS-Cow::eGFP) lines (Chang and Sun, 2014) were obtained from Yi Henry Sun (Institute of Molecular Biology, Academia Sinica, 
Taipei, Taiwan). The cow ${ }^{G D P}$ \#03259 (y[1] w[*]; Mi\{y [+mDint2]=MIC\}Cow[MI03259]/TM3, Sb[1] Ser[1]) and cow $^{G D P} \quad \# 12802$ (y[1] w[*]; Mi\{y[+mDint2]=MIC\}Cow [Ml12802]) mutants, and the cow Df \#6193 (w[1118]; Df (3R)Exel6193, P $\{\mathrm{w}[+\mathrm{mC}]=X P-U\}$ Exel6193/TM6B, Tb[1]) and cow Df \#619 (w[1118]; Df(3R)BSC619/TM6C, cu[1] $\mathrm{Sb}[1])$ deficiencies were all obtained from the Bloomington Drosophila Stock Center (stock \#40757, \#58669, 7672, and 25694, respectively; Indiana University, Bloomington, IN). Cow-Gal4 was obtained from the Vienna Tile (VT) collection of the Vienna Drosophila Resource Center (VT046086; Vienna, Austria). Neuronal vesicular glutamate transporter (vglut)-Gal4 and muscle-specific 24B-Gal4 driver lines were obtained from the Bloomington Drosophila Stock Center. The MHC-CD8-GCaMP6f-Sh Ca ${ }^{2+}$ reporter (SynapGCaMP6f; Newman et al., 2017) was obtained from Ehud Isacoff (University of California, Berkeley, CA). Control wg\{KO; FRT Wg FRT QF; pax-Cherry $\}$ and membrane-tethered wg $\{K O$; FRT NRT-Wg FRT QF; pax-Cherry\} (Alexandre et al., 2014) were obtained with permission from Andrea Page-McCaw (Department of Cell and Developmental Biology, Vanderbilt University, Nashville, TN). Null notum ${ }^{K O}(4)(w+)$ (Kakugawa et al., 2015) was obtained from Jean-Paul Vincent (Francis Crick Institute, London, UK).

\section{PCR/RT-PCR studies}

Staged Drosophila eggs were dechorionated using bleach for $30 \mathrm{~s}$, washed with distilled $\mathrm{H}_{2} \mathrm{O}\left(\mathrm{dH}_{2} \mathrm{O}\right)$ three times, and embryos were genotyped using a GFP marker with an epifluorescent microscope. Five embryos per genotype were homogenized in $10 \mu \mathrm{l}$ of Gloor and Engels DNA extraction buffer (10 mM Tris $\mathrm{HCL}, \mathrm{pH} 8.2 ; 1 \mathrm{~mm}$ EDTA, pH 8.0; $25 \mathrm{~mm} \mathrm{NaCl}$; and $200 \mu \mathrm{g} / \mathrm{ml}$ Proteinase K) with a glass rod in an Eppendorf tube, and the homogenate was incubated at $37^{\circ} \mathrm{C}$ for $30 \mathrm{~min}$, and then at $95^{\circ} \mathrm{C}$ for 2 min. For each PCR, $\sim 10 \mathrm{ng}$ of DNA was used with the following primers: forward 5'-GCAACATTCTGGCTTCGTGTCATGC-3' and reverse 5'-CTCTCGACTTGCAAATAGCAGACGATGATC-3' for the cow gene (product size, 1927); and forward 5'-GTGGAAAAGCGGTTGAAATAGGG-3' and reverse 5'-GTCCACATCCACAAAGATGCC-3' for the dfmr1 gene control (product size, 3850). For the RT-PCR studies, one embryo per genotype was used with the RNeasy Micro Kit (catalog \#74004, Qiagen) to extract RNA. The OneStep RT-PCR Kit (catalog \#210212, Qiagen) was used. For each reaction, $\sim 7 \mathrm{ng}$ of RNA was used with the following primers: forward 5'-AGAACAGCAACTTGAATGCCTATC-3' and reverse 5'-CGAAGCATCTGCACCATTCC-3' for the cow gene (product size, 348); and forward 5'-TAAACTGCGAGAGGTTTTCC-3' and reverse 5' ATTCGATGAGTGTACGCTG-3' for the dmgalectin gene control (product size, 321). Products were loaded on a $0.8 \%$ agarose gel in TAE buffer with purple gel loading dye (catalog \#B7025S, New England Biolabs) and SYBR safe DNA gel stain (catalog \#S33102, Thermo Fisher Scientific), and run at $100 \mathrm{~V}$ for $30 \mathrm{~min}$.

\section{Cow antibodies}

We used a well characterized, published anti-Cow antibody (Chang and Sun, 2014). New rabbit anti-Cow antibodies were also made by ABclonal against amino acids 36-236. Three antiserums were recovered and affinity purified $(29,30,31)$. Cow antibody 31 was preabsorbed against cow nulls (cow ${ }^{G D P}$ ) for imaging studies. Cow antibody 31 was used for Figures 1, 2 and 4).

\section{Western blotting}

Staged Drosophila eggs (18-24 h postfertilization for maximum expression; www.fruitfly.org) were dechorionated using bleach for $30 \mathrm{~s}$ and washed with $\mathrm{dH}_{2} \mathrm{O}$ three times, and embryos were genotyped using a GFP marker with an epifluorescent microscope. Twenty-five embryos were placed into an Eppendorf tube with $24 \mu \mathrm{l}$ RIPA buffer (150 mm sodium chloride, $1 \%$ Triton $X-100,0.5 \%$ sodium deoxycholate, $0.1 \%$ sodium dodecyl sulfate, $50 \mathrm{~mm}$ Tris) and protease inhibitor cocktail (catalog \#P8340, SigmaAldrich), then immediately snap frozen in a dry ice ethanol bath. Samples were sonicated (settings: $90 \%$ duty, output 2; Sonifier 250, Branson) for $20 \mathrm{~s}$, vortexed (speed 4; Standard Mini Vortexer, VMR Scientific Products) for $5 \mathrm{~s}$, and then centrifuged at $14,000 \mathrm{rpm}$ for $10 \mathrm{~min}$. The supernatant was then transferred to new tubes with $1 \times$ Invitrogen NuPage LDS buffer (catalog \#NP007, Thermo Fisher Scientific) and 5\% 2-mercaptoethanol (catalog \#M7154, Sigma-Aldrich), then vortexed as above. Samples were incubated at room temperature for $20 \mathrm{~min}$, heated at $100^{\circ} \mathrm{C}$ for $10 \mathrm{~min}$, then centrifuged as above. Equal volumes of lysate were loaded into precast NuPage 4-12\% Invitrogen Bis-Tris gels (catalog \#NP0336, Thermo Fisher Scientific) with Life Technologies NuPage running buffer (catalog \#NP002, Thermo Fisher Scientific) and Invitrogen NuPage antioxidant (catalog \#NP0005, Thermo Fisher Scientific). Electrophoresis was performed at $150 \mathrm{~V}$ for $2 \mathrm{~h}$. Protein was then transferred overnight at $4^{\circ} \mathrm{C}$ with constant $30 \mathrm{~mA}$ current to nitrocellulose membranes (catalog \#Protran NBA085C001EA, PerkinElmer) in the Life Technologies NuPage transfer buffer (catalog \#NP0006-1, Thermo Fisher Scientific) supplemented with $20 \%$ methanol (catalog \# AH230-4, Honeywell). Following transfer, membranes were rinsed with $\mathrm{dH}_{2} \mathrm{O}$, air dried at room temperature for $1 \mathrm{~h}$, and then blocked with $2 \%$ nonfat powdered milk in TBS-T (0.1\% Tween-20, $150 \mathrm{~mm}$ sodium chloride, $5 \mathrm{~mm}$ potassium chloride, and $25 \mathrm{~mm}$ Tris, $\mathrm{pH}$ 7.6) at room temperature for $1 \mathrm{~h}$ with rotation. Primary antibodies were incubated overnight in $2 \%$ milk in TBST. Membranes were then washed in TBST (five times for 6 $\mathrm{min}$ ), followed by incubation in secondary antibody at room temperature in $2 \%$ milk in TBST for $1 \mathrm{~h}$ with rotation, and washed again as before. Imaging was performed on a $\mathrm{LI}-$ COR Odyssey Imager with analysis on Image Studio Lite (LI-COR). Total protein was assessed via the REVERT total protein stain (catalog \#926-11011, LI-COR). Primary antibodies: rabbit anti-Cow (Ab 31, this study) and goat antiGFP (catalog \#ab6662, Abcam), both at 1:1000. The following secondary antibodies were used: IRDye 680 donkey anti-rabbit (catalog \#926-68 073, LI-COR) and IRDye 800 donkey anti-goat (catalog \#926-32214, LI-COR), both at $1: 10,000$. 

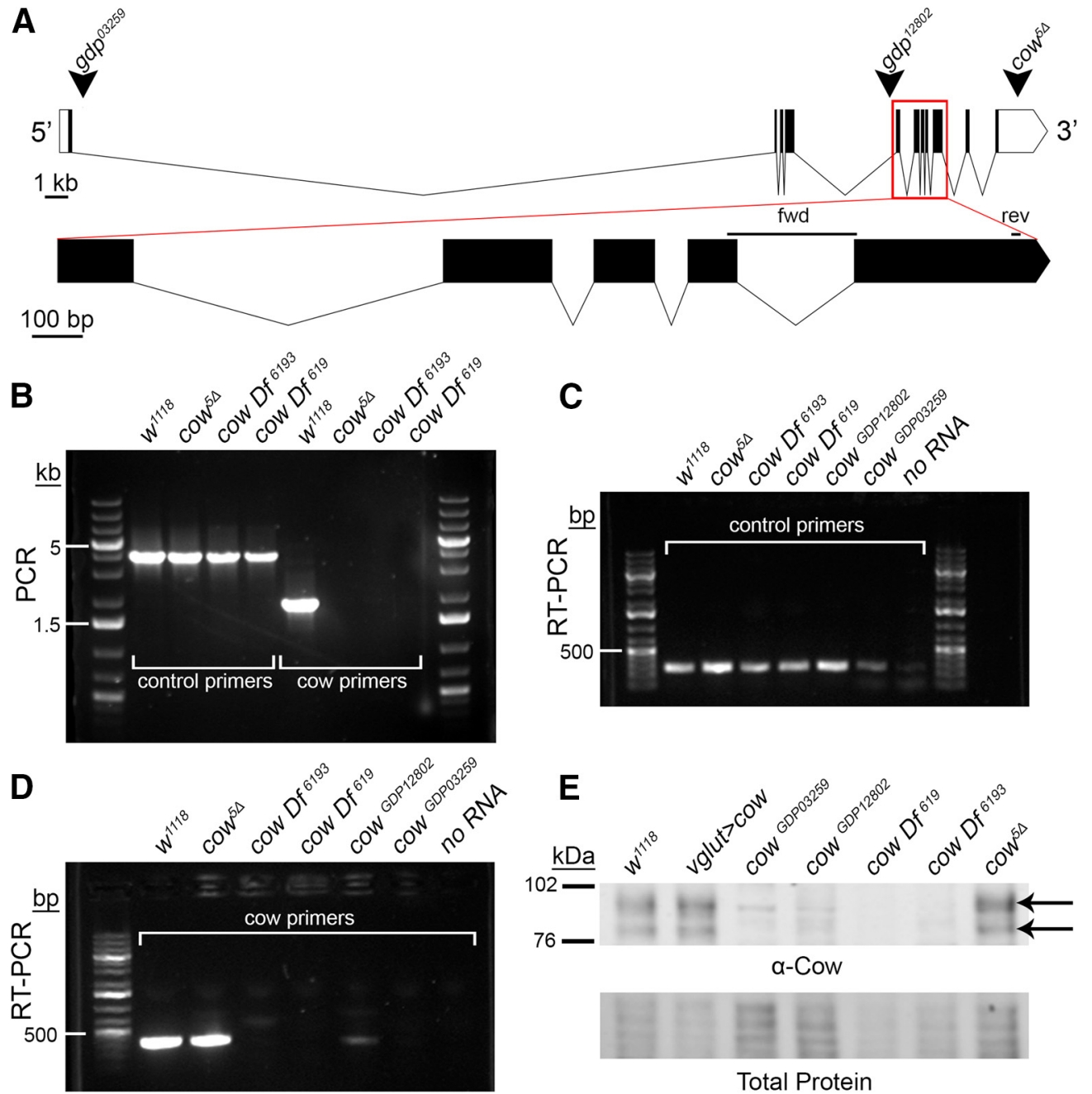

Figure 1. Carrier of Wingless (Cow) genetic locus and mutant characterization. $\boldsymbol{A}$, Intron/exon structure of the cow gene (transcript cow-RD; flybase.org). Arrowheads indicate gene disruption project (gdp) inserts in two different lines (03259 and 12802). The third arrowhead indicates where the published $\operatorname{cow}^{5 \Delta}$ deletion begins in the $3^{\prime}$ UTR and runs 9119 bp downstream (Chang and Sun, 2014). Below, the expanded region outlined with the red box is labeled "fwd" and "rev" to depict the RT-PCR primer pair. B, PCR products from the genotypes listed. Control (dfmr1 gene) and cow primers from the region of the cow ${ }^{5 \Delta}$ deletion. $\boldsymbol{C}, \boldsymbol{D}, \mathrm{RT}-\mathrm{PCR}$ products from the genotypes listed using both control (dmgalectin gene) and cow primers. E, Western blot of the indicated genotypes using an anti-Cow antibody, with the total protein stain shown below. The two arrows indicate Cow protein with and without GAG chains.

\section{Confocal imaging}

Wandering third instars were dissected in physiological solution containing the following (in $\mathrm{mm}$ ): $128 \mathrm{NaCl}, 2 \mathrm{KCl}$, $0.2 \mathrm{CaCl}_{2}, 4 \mathrm{MgCl}_{2}, 70$ sucrose, 5 HEPES \{2-[4-(2-hydroxyethyl)piperazin-1-yl]ethanesulfonic acid\} at $\mathrm{pH}$ 7.2. The samples were fixed with $4 \%$ paraformaldehyde (catalog \#15714, EMS) diluted in PBS (catalog \#46-013-CM, Corning). For intracellular labeling, samples were permeabilized with $0.2 \%$ Triton X-100 (catalog \#BP151-100, Thermo Fisher Scientific) three times for 10 min each. Embryos were bleached for dechorionation, fixed with heptane and paraformaldehyde, and devitillinized with methanol. The following primary antibodies were used: mouse anti-Discs Large (DLG; 1:250; catalog \#4F3), mouse anti-Wg (1:1; catalog \#4D4), and mouse anti-Brp (1:200, catalog \#nc82), all from the Developmental Studies Hybridoma Bank; Alexa Fluor 488-conjugated goat anti-horseradish peroxidase (HRP; 1:250; catalog \#123-545-021), Cy3-conjugated goat anti-HRP (1:250; catalog \#123-165-021), and Alexa Fluor 647-conjugated goat anti-HRP (catalog \#123-605-021; 1:250), all from Jackson ImmunoResearch; rabbit anti-GluRIIC (1:5000; Marrus et al., 2004); and rabbit anti-GFP (1:1500; catalog \#ab290, abcam). Preparations were incubated with primary antibodies overnight at $4^{\circ} \mathrm{C}$ and secondary antibodies at room temperature for $2 \mathrm{~h}$, washed three times for 10 min each, and then mounted in Fluoromount-G (catalog \#17984-25, EMS) onto $25 \times 75 \times 1 \mathrm{~mm}$ slides (Fisher Scientific, 12-544-2) with a $22 \times 22-1$ coverslip (catalog \#12-542-B, Thermo Fisher Scientific) and sealed with clear nail polish (Sally Hansen). Imaging was performed on a Zeiss LSM 510 META laser-scanning confocal microscope, with images projected in Zen (Zeiss) and analyzed using Image $(\mathrm{NIH})$. NMJ intensity measurements were 

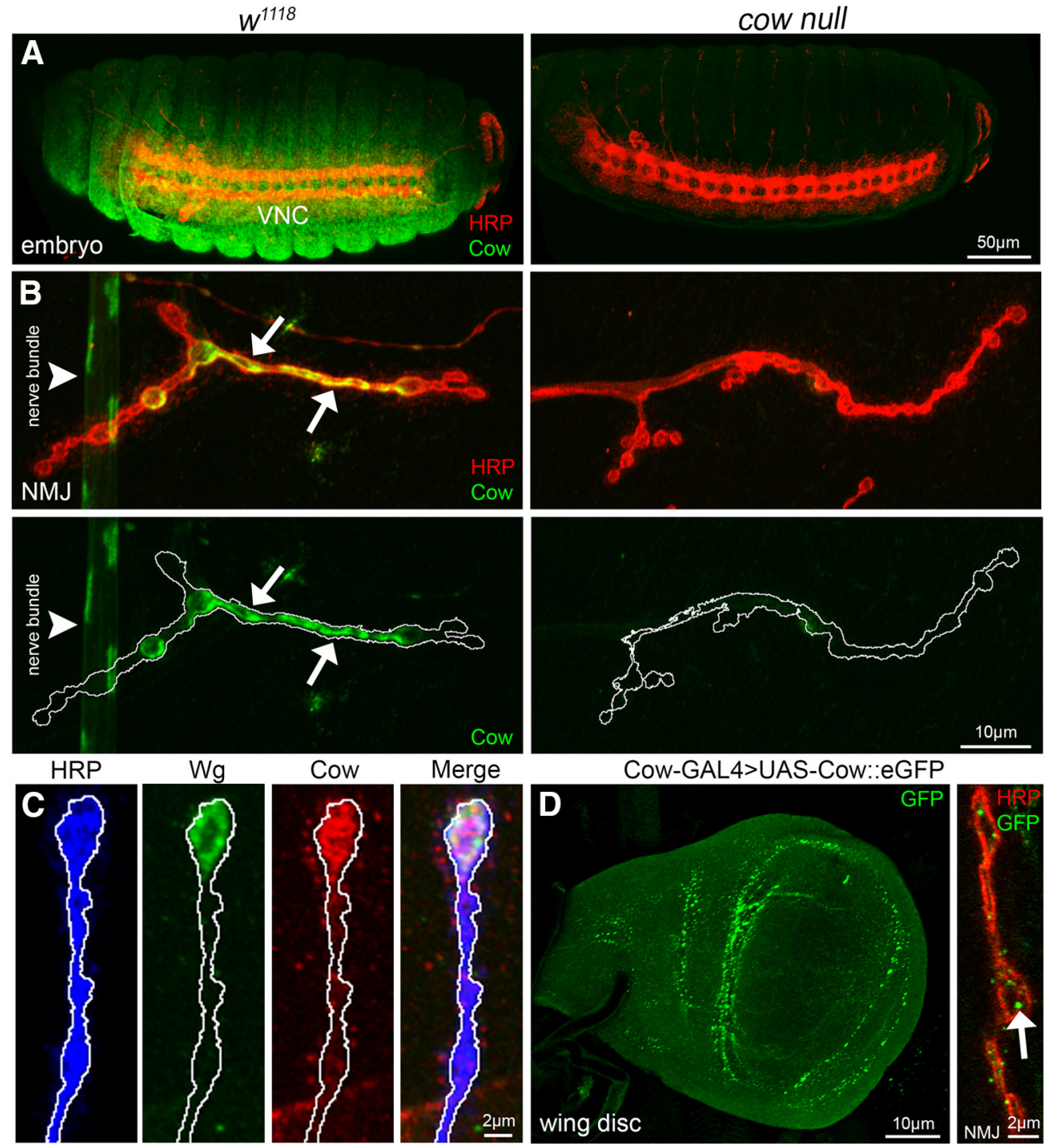

Figure 2. Cow expression in embryos, larval NMJ synaptic terminal, and wing disk. $\boldsymbol{A}$, Confocal images of stage 16 embryos colabeled with anti-HRP (red) to mark neuronal membranes and anti-Cow (green) in genetic background control ( $w^{1118}$, left) and cow null (cow ${ }^{G D P} /$ cow $^{G D P}$, right). The ventral nerve cord (VNC) is labeled. B, Confocal images of third instar NMJ colabeled with antiHRP (red) and anti-Cow (green) in control ( $w^{1118}$, left) and cow null (cow GDP/cow GDP, right). From nonpermeabilized labeling, Cow appears secreted from a dynamic subset of synaptic boutons (arrows) and also present in the nerve bundle (arrowhead). Cow is shown without HRP in below images. White line marks the NMJ terminal HRP domain. $\boldsymbol{C}$, Higher-magnification images of $w^{1118}$ NMJ synaptic boutons colabeled with anti-HRP (blue), anti-Wg (green), and anti-Cow (red), with merged image on right. White line marks the NMJ terminal HRP domain. $\boldsymbol{D}$, Cow-GAL4 driving UAS-Cow::eGFP in wandering third instar wing imaginal disk (left) and NMJ colabeled with anti-HRP (red) and anti-GFP (green, right). For the NMJ, a single confocal section (0.5 $\mu \mathrm{m})$ shows Cow punctae (arrow) within and surrounding synaptic boutons.

made with HRP signal-delineated $z$-stack areas of maximum projection using ImageJ threshold and wand-tracing tools.

\section{Two-electrode voltage-clamp electrophysiology}

Wandering third instars were dissected longitudinally along the dorsal midline, internal organs were removed, and body walls were glued down (Vetbond, 3M). Peripheral motor nerves were cut at the base of the ventral nerve cord (VNC). Dissections and two-electrode voltage-clamp (TEVC) recordings were both conducted at $18^{\circ} \mathrm{C}$ in physiological saline as follows (in mm): $128 \mathrm{NaCl}, 2 \mathrm{KCl}$, $4 \mathrm{MgCl} 2,1.5 \mathrm{CaCl} 2,70$ sucrose, and 5 HEPES, pH 7.2. Preparations were imaged using a Zeiss Axioskop microscope with a Zeiss 40x water-immersion objective. Muscle 6 in abdominal segments 3-4 was impaled with two intracellular electrodes $(1 \mathrm{~mm}$ outer diameter borosilicate capillaries; catalog \#1B100F-4, World Precision Instruments) of $\sim 15 \mathrm{M} \Omega$ resistance filled with $3 \mathrm{M} \mathrm{KCl}$. The muscles were clamped at $-60 \mathrm{mV}$ using an Axoclamp-2B amplifier (Axon Instruments). Spontaneous miniature excitatory junction current $(\mathrm{mEJC})$ recordings were made in continuous 2 min sessions and low-pass filtered. For EJC 
records, the motor nerve was stimulated with a fire-polished suction electrode using $0.5 \mathrm{~ms}$ suprathreshold voltage stimuli at $0.2 \mathrm{~Hz}$ from a Grass S88 stimulator. Nerve stimulation-evoked EJC recordings were filtered at $2 \mathrm{kHz}$. To quantify EJC amplitude, 10 consecutive traces were averaged, and the average peak value was recorded. Clampex 9.0 was used for data acquisition, and Clampfit 9 was used for data analysis (Axon Instruments).

\section{SynapGCaMP imaging}

For SynapGCaMP quantal imaging experiments, wandering third instars were dissected and type $1 \mathrm{~b}$ NMJs were imaged in physiological saline as follows (in $\mathrm{mm}$ ): 70 $\mathrm{NaCl}, 5 \mathrm{KCl}, 1.5 \mathrm{CaCl}_{2}, 25 \mathrm{MgCl}_{2}, 10 \mathrm{NaHCO}_{3}, 5$ trehalose, 115 sucrose, and 5 HEPES, pH 7.2. Fluorescence images were acquired with a Vivo Spinning Disk Confocal microscope (3i Intelligent Imaging Innovations), with a $63 \times 1.0$ numerical aperture (NA) water-immersion objective (Zeiss), LaserStack $488 \mathrm{~nm}(50 \mathrm{~mW})$ laser, Yokogawa CSUX1 A1 spinning disk, and EMCCD camera (Photometrics Evolve). Image capture and analysis were performed as reported previously (Newman et al., 2017). Briefly, spontaneous events were imaged at $20 \mathrm{~Hz}(50 \mathrm{~ms}$ exposures, in streaming capture mode) for $30 \mathrm{~s}$. Movies 1, 2 were then filtered, registered, and bleach corrected prior to $\Delta F$ conversion. Using the $\delta \Delta F$ data, an XYT local maxima algorithm was applied to the thresholded $\Delta F$ data to identify where and when quantal release events occur (Newman et al., 2017). Quantal coordinates were used to calculate $\Delta F / F$ amplitudes and frequencies (normalized to the baseline SynapGCaMP6f 2D area).

\section{Structured illumination microscopy}

Dissected wandering third instar preparations were imaged using a Nikon N-SIM in 3D SIM (structured illumination microscopy) mode, configured with a 100× EX V-R diffraction grating, automated TiE inverted fluorescence microscope stand, $100 \times$ SR Apo 1.49 NA objective, Andor DU-897 EM-CCD, and 488/561 nm lasers. Image acquisition was managed through NIS-Elements (Nikon Instruments), and stacks were acquired with a $0.12 \mu \mathrm{m}$ step size. Stack reconstruction of the raw data were used prior to rendering and analysis. To acquire larger fields of view and capture whole NMJs, SIM images were stitched together using the automated tiling method within NISElements software.

\section{Laser-scanning confocal imaging analysis}

We used Imaris Version 9.3.0 to quantify LSM (laserscanning confocal imaging) images using the "surfaces" function to identify the number and volume of Brp punctae, as follows:

1. Open image file and click "add new surfaces" to start the wizard.

2. Algorithm settings click "segment only a region of interest" $(\mathrm{ROI})$.

3. Select ROI in $X, Y$, and $Z$.

4. Select "source channel" and thresholding conditions.

5. Adjust threshold until all spots are selected.

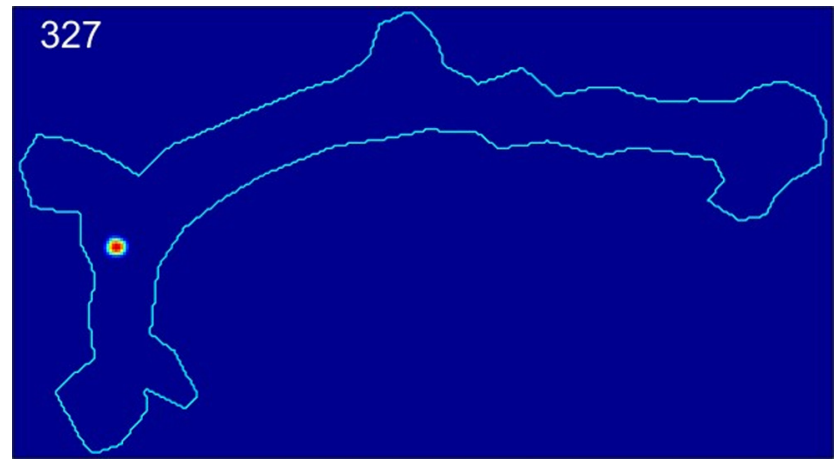

Movie 1. SynapGCaMP imaging of spontaneous quantal events in the control NMJ. Example of muscle 4 type $1 \mathrm{~b}$ NMJ imaged in the control (vglut-Gal4/+; SynapGCaMP6f/+) with quantified data shown in Figure 4. [View online]

6. Enable "split touching objects" with seed points diameter $(0.4 \mu \mathrm{m})$.

7. Use "quality filter" to adjust selections with minimal background.

8. Click "finish" to execute all creation steps and exit the wizard.

9. Click "edit" tab and delete extraneous spots by hand.

10. Click "statistics" tab and export values to Microsoft Excel.

\section{SIM image analysis}

We used Imaris Version 9.3.0 to quantify SIM images using the "spots" function to identify the number of Brp punctae and GluR clusters, as follows:

1. Open image file and click "add new spots" to start the wizard.

2. Algorithm settings click "segment only a region of interest" with "different spot sizes (region growing)."

3. Select ROI in $X, Y$, and $Z$.

4. Select "source channel" and click "background subtraction."

5. Classify spots with a "quality" filter type and adjust by eye.

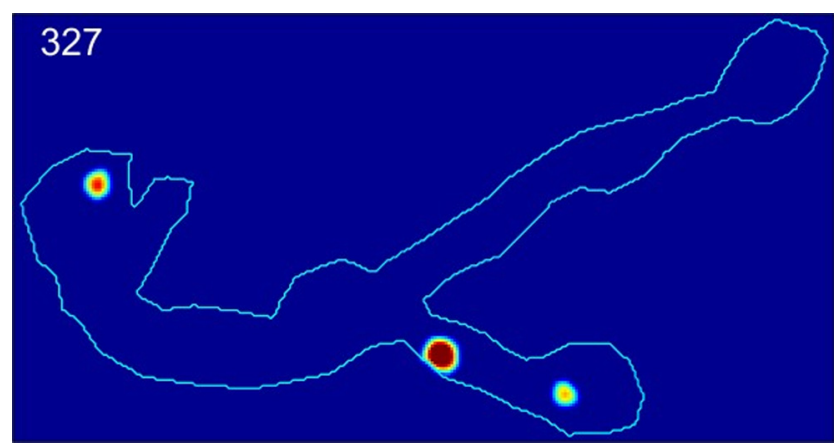

Movie 2. SynapGCaMP imaging of spontaneous quantal events in cow KD NMJ. Example of muscle 4 type 1b NMJ imaged following motor neuron-targeted cow RNAi (vglut-Gal4>UAScow-RNAi; SynapGCaMP6f/+) with quantified data shown in Figure 4. [View online] 
6. Spot regions click "local contrast."

7. Region threshold with diameter from "region volume."

8. Click "finish" to execute all creation steps and exit the wizard.

9. Click "edit" tab and delete extraneous spots by hand.

10. Click "statistics" tab and export values to Microsoft Excel.

\section{Statistical analyses}

All statistical measurements were performed within GraphPad Prism (version 7.04 for Windows). The D'Agostino-Pearson K-squared normality test was performed on all datasets to check for normality. For comparisons of two genotypes, a $t$ test (normally distributed) or Mann-Whitney test (not normally distributed) was performed. For all other comparisons of more than two genotypes, an ordinary one-way ANOVA (normally distributed) or Kruskal-Wallis test (not normally distributed) was performed. All graphs were made in Prism, and the data are represented in scatter plots with the mean \pm SEM.

\section{Results}

\section{Carrier of wingless (cow) genetic locus, mutants and expression profiles}

The cow gene encodes three transcripts (cow-RC, cow-RD, cow-RE), with cow-RD containing a long $3^{\prime}-\mathrm{UTR}$ (Fig. $1 A)$. We acquired a reported cow null mutant $\left(\operatorname{cow}^{5 \Delta}\right.$; Chang and Sun, 2014), two mutations from the Gene Disruption Project (cow ${ }^{G D P} 03259$ and 12802; Bellen et al., 2004; Nagarkar-Jaiswal et al., 2015), and two cow deficiencies from the Bloomington Drosophila Stock Center (Df[619] and Df[6193]). The cow ${ }^{5 \Delta}$ mutant has a $9119 \mathrm{bp}$ deletion starting in the $3^{\prime}$-UTR that does not remove cow coding sequence, but is published as a well characterized protein null (Chang and Sun, 2014). The cow ${ }^{G D P}$ lines are minos-mediated integration cassette (Mi\{MIC\}) insertions; 03259 in cow intron 1, and 12802 in cow intron 4. Df[619] completely removes cow and 31 other genes, while cow Df[6193] removes cow and 41 other genes. PCR tests were performed using primers in the $\operatorname{cow}^{5 \Delta}$ deletion region (Fig. 1A). As expected, there are no PCR products from cow ${ }^{5 \Delta}$ or either cow Df (Fig. 1B). Next, RT-PCR tests were performed using primers spanning an exon-exon junction to ensure mRNA amplification (Fig. 1A). The RNA extraction was confirmed using primers for a control gene (dfmr1; Fig. 1C). The cow transcript in the genetic background control $w^{1118}$ is present at similar levels in the cow $^{5 \Delta}$ line (Fig. 1D). There is no detectable cow transcript in either of the cow Dfs, or in one of the cow gdp lines (03259), and only a very faint product in the other cow ${ }^{\text {gdp }}$ line (12802; Fig. 1D). Thus, cow ${ }^{\text {gdp }} 03259$ is an RNA null allele.

The published $\operatorname{cow}^{5 \Delta}$ mutation has been reported to have transcript levels similar to those of wild type, but to have no detectable Cow protein expression (Chang and Sun, 2014). We therefore next examined protein levels via Western blotting using the published, well characterized Cow antibody (Chang and Sun, 2014), as well as three new antibodies made for this study (see Materials and
Methods). Cow protein has a predicted molecular weight of $\sim 75 \mathrm{kDa}$ (without HS chains) and $\sim 100 \mathrm{kDA}$ (with HS chains). The two Cow protein bands are clearly present in the $w^{1118}$ controls and absent in both cow deficiency lines (Fig. 1E). Cow protein is also undetectable in the cow ${ }^{g d p}$ lines, even at heightened levels of protein loading (Fig. $1 E$ ). In stark contrast to previously published work (Chang and Sun, 2014), both Cow protein bands are present at normal levels in cow ${ }^{5 \Delta}$ mutants (Fig. $1 E$, arrows). In our studies, $c 0 w^{5 \Delta}$ mutants typically die as early-stage larvae, and the few escapers can be raised to the third instar only with constant care. In contrast, both cow ${ }^{g d p}$ protein nulls are fully adult viable, both as homozygotes and as heterozygotes over Df[619]. Thus, our evidence indicates that cow $^{5 \Delta}$ does not affect Cow expression, but has a second site larval lethal mutation. Further, the Cow protein is not required for full adult viability. For the remainder of experiments, cow ${ }^{\text {gdp }} 03259$ and cow Df[619] were used, as both show complete removal of Cow RNA and protein.

To assess Cow protein expression in controls and null mutants, we performed anti-Cow labeling and Cow-Gal4 to drive UAS-Cow::eGFP (Fig. 2). In control embryos, Cow is widely expressed, including localization in the VNC (Fig. $2 A$ ). In cow null mutants (cow ${ }^{G D P} /$ cow $^{G D P}$ ), antibody labeling is undetectable (Fig. $2 A$, right). Since Cow has a signal peptide, and has been previously established to be secreted (Chang and Sun, 2014), we tested Cow expression at the NMJ using antibody labeling with nonpermeabilizing conditions. In the $w^{1118}$ control wandering third instar NMJ, Cow appears secreted from a dynamic subset of type 1 b synaptic boutons (Fig. $2 B$, arrows). Cow is also present in a punctate pattern along the peripheral nerve bundle (arrowhead). In cow nulls, neuronal and synaptic antibody labeling is lost (Fig. $2 B$, right). Within NMJ synaptic boutons colabeled for both Cow and $\mathrm{Wg}$ antibody, the two secreted proteins have overlapping expression patterns, colocalizing in the extracellular synaptomatrix surrounding the same boutons (Fig. 2C). Using Cow-Gal4 to drive a UAS-Cow::eGFP, GFP is present throughout the wandering third instar wing imaginal disk, including punctae surrounding the wing pouch (Fig. 2D, left). Cow::eGFP is also present at the NMJ in punctae within and surrounding the synaptic boutons within a single confocal slice (Fig. 2D, right). Overall, Cow is expressed in both neuronal and non-neuronal tissue in embryos, larvae, and imaginal discs, and colocalizes with $\mathrm{Wg}$ at the NMJ.

\section{Presynaptic cow restricts NMJ growth and synaptic bouton formation}

Wg trans-synaptic signaling regulates NMJ growth and synaptic bouton formation (Packard et al., 2002), thus we hypothesized that if Cow regulates $\mathrm{Wg}$ at the NMJ, Cow loss should affect the NMJ architecture. Each NMJ terminal consists of a relatively stereotypical muscle innervation pattern, with a consistent number of axon branches and large synaptic boutons (Menon et al., 2013). Wg signaling bidirectionally regulates synaptic development, with $W g$ knockdown decreasing NMJ synaptic bouton number and $\mathrm{Wg}$ OE increasing boutons (Packard et al., 
2002; Kopke et al., 2017), including an increase in satellite boutons [small boutons connected to the mature (parent) bouton or adjacent axon; Torroja et al., 1999; Gatto and Broadie, 2008]. To test Cow requirements in synaptic architectural development, we labeled the wandering third instar NMJ. Anti-HRP was used to label the NMJ terminal by binding to extracellular fucosylated $\mathrm{N}$-glycans associated with the presynaptic neural membrane (Jan and Jan, 1982; Parkinson et al., 2013). Anti-DLG was used to label the postsynaptic scaffold in the subsynaptic reticulum (SSR; Lahey et al., 1994; Parnas et al., 2001). We used cow GDP/Df (referred to as cow null) to eliminate cow globally, and characterized cow RNAi lines (Chang and Sun, 2014) for both motor neuron (vglut-Gal4) and muscle (24B-Gal4) cell-targeted knock-down studies. Sample images and the summary of results are shown in Figure 3.

Cow restrains NMJ development, specifically restricting synaptic bouton formation. When Cow is knocked out completely, there is a clear increase in boutons (Fig. $3 A$, left). In quantified measurements, cow nulls show a very significant increase in synaptic bouton number $\left(w^{1118}\right.$, $25.53 \pm 1.37$ vs cow ${ }^{G D P} / D f, 41.13 \pm 1.6 ; p<0.0001$; Fig. $3 A$, right). With targeted cow knockdown in presynaptic motor neurons (vglut-Gal4>cow-RNAi), there is the same increase in NMJ bouton formation (Fig. 3B), indicating that Cow originates from the neuron. Interestingly, presynaptic Cow knockdown also increases the number of satellite boutons (Fig. 3B; inset). Presynaptic cow knockdown causes very significantly elevated mature bouton numbers (vglut-Gal4/+, 26.69 \pm 1.49 vs vglut $>$ cowRNAi, $37.38 \pm 1.75 ; p=0.0002)$ as well as an increased percentage of satellite boutons (vg/ut-Gal4/+, $2.9 \pm$ $0.89 \%$ vs vglut $>$ cow $-R N A i, 5.77 \pm 1.86 ; p=0.061$; Fig. $3 B$, right). Conversely, postsynaptic cow knockdown (24B-Gal4>cow-RNAi) causes no discernable differences from the controls (Fig. $3 C$, right). Mature and satellite bouton quantifications demonstrate no effect of removing Cow from the muscle (mature; $24 B /+, 30.63 \pm 1.73$ vs $24 B>$ cow $-R N A i$, $28.06 \pm 1.04 ; p>0.9999$; Fig. $3 C$, right; Table 1, satellite results). Together, these results show Cow originating from the presynaptic motor neuron restricts the formation of NMJ synaptic boutons.

When Cow is overexpressed in motor neurons (vglutGal4>UAS-Cow), Cow is elevated at the NMJ with a concomitant decrease in extracellular Wg ligand (Fig. 4A). The NMJs have a typical number of mature boutons, but an increase in satellite boutons (Fig. 4B). Interestingly, cow neuronal OE causes HRP redistribution with distinct spots of accumulation (Fig. 4B, heatmap on right). Quantification shows a significant increase in Cow levels secreted at the NMJ terminal (normalized vg/ut-Gal4/+, $1.0 \pm 0.06$ vs vglut $>$ cow, $3.04 \pm 0.06 ; p<0.0001$ ), with a significant decrease in extracellular $\mathrm{Wg}$ levels (vglut-Gal4/+, $1.0 \pm 0.08$ vs vglut $>$ cow, $0.67+0.06 ; p=0.001$; Fig. $4 C$ ). Quantification shows no change in bouton number (vglut-Gal4/+, $25.25 \pm 0.81$ vs vglut $>$ Cow, $27.06 \pm 1.4 ; p=0.27$ ), but a significant increase in satellite boutons (vglut-Gal4/+, $2.33 \pm 0.94 \%$ vs vglut $>$ cow, $7.12 \pm 0.67 ; p=0.0003$; Fig. $4 D$ ). Whereas neuronal cow OE elevates normal Cow expression at the NMJ, muscle cow OE causes aberrant, ectopic expression (normalized $24 B-G a l 4 /+, 1.0 \pm 0.03$ vs $24 B>$ cow, $3.91 \pm 0.23 ; p<0.0001)$, which increases Wg ligand $(24 B-G a l 4 /+, 1.0 \pm 0.07$ vs $24 B>$ Cow $1.52 \pm 0.14$; $p=0.003$ ). Muscle-targeted cow OE causes no change in mature boutons $(24 B-G a l 4 /+, 30.38 \pm 1.94$ vs $24 B>$ cow, $29.81 \pm 1.46 ; p=0.82$ ) or the percentage of satellite boutons $(24 B-G a l 4 /+, \quad 3.16 \pm 1.16 \%$ vs $24 B>$ cow, $5.48 \pm 1.58$; $p=0.2486$ ). We next assayed synaptic functional differentiation to test whether these structural changes have functional consequences.

\section{Cow restricts presynaptic vesicle fusion and neurotransmission strength}

We used the following two methods to assay NMJ synaptic functional differentiation and neurotransmission strength: (1) TEVC electrophysiology (Dani et al., 2012; Parkinson et al., 2013; Kopke et al., 2017); and (2) imaging genetically encoded calcium reporter SynapGCaMP6f (Newman et al., 2017). For assaying evoked transmission, muscle 6 was clamped $(-60 \mathrm{mV})$, while the motor nerve was stimulated with a suction electrode $\left(1.5 \mathrm{~mm}\left[\mathrm{Ca}^{2+}\right]\right)$. EJC traces were recorded $(0.2 \mathrm{~Hz}, 10$ consecutive stimuli) to measure the average amplitude. For assaying mEJC events, spontaneous synaptic vesicle fusions were recorded, measuring frequency and amplitude. The mEJC frequency indicates presynaptic vesicular release (number of active synapses, fusion probability), and mEJC amplitude indicates number of activated postsynaptic receptors. For quantal imaging, the SynapGCaMP reporter (MHC-CD8-GCaMP6f-Sh) contains a myosin heavy chain (MHC) promoter for muscle targeting, CD8 transmembrane domain for membrane targeting, and Shaker (Sh) $\mathrm{K}^{+}$channel C-terminal tail for postsynaptic targeting (Newman et al., 2017). By imaging transmission, we are able to specifically determine the changes in quantal activity at the convergent motor neuron inputs separately. Live-imaging recordings were made of the SynapGCaMP reporter at muscle 4, with spontaneous event frequency divided by the NMJ synaptic area, and event amplitude measured as the change in the fluorescence signal over the baseline NMJ fluorescence $\left(\Delta F / F_{0}\right)$. Representative recordings and summarized data are shown in Figure 5.

With nerve stimulation, evoked transmission is clearly and consistently increased in cow nulls compared with $w^{1118}$ controls (Fig. 5A). Quantified measurements show EJC amplitude significantly elevated $\left(w^{1118}, 175.4 \pm 9.93 \mathrm{nA}\right.$ vs cow GDP, $214.6 \pm 12.24 ; p=0.023 ; w^{1118}, 175.4 \pm 9.93$ vs cow ${ }^{G D P} / D f, 254.2 \pm 14.99 ; p=0.012$; Fig. $5 B$ ). Although the cow $^{G D P} / D f$ mutants show a slight increase in mEJC frequency, no change was observed in the cow ${ }^{G D P}$ nulls. We found no change in amplitude (Fig. $5 C$ ). In quantified measurements, mEJC frequency is slightly increased in homozygous mutants and more increased in the cow GDP $/ D f\left(w^{1118}\right.$, $1.396 \pm 0.19 \mathrm{~Hz}$ vs cow ${ }^{G D P} /$ cow $^{G D P}, 1.764 \pm 0.23 ; p=0.58$; $w^{1118}, 1.396 \pm 0.19$ vs cow ${ }^{G D P} / D f, 2.41 \pm 0.49 ; p=0.05$; Fig. $5 D$, left). There is no significant change in $\mathrm{mEJC}$ amplitude $\left(w^{1118}, 0.75 \pm 0.03 \mathrm{nA}\right.$ vs cow ${ }^{G D P} /$ cow $^{G D P}, 0.87 \pm 0.06$; $p=0.189 ; w^{1118}, 0.75 \pm 0.03 \mathrm{nA}$ vs cow ${ }^{G D P} / D f, 0.72 \pm 0.05$; $p=0.886$; Fig. $5 D$, right). Neuronally targeted cow-RNAi causes an increase in mEJC frequency (vglut-Gal4/+, 


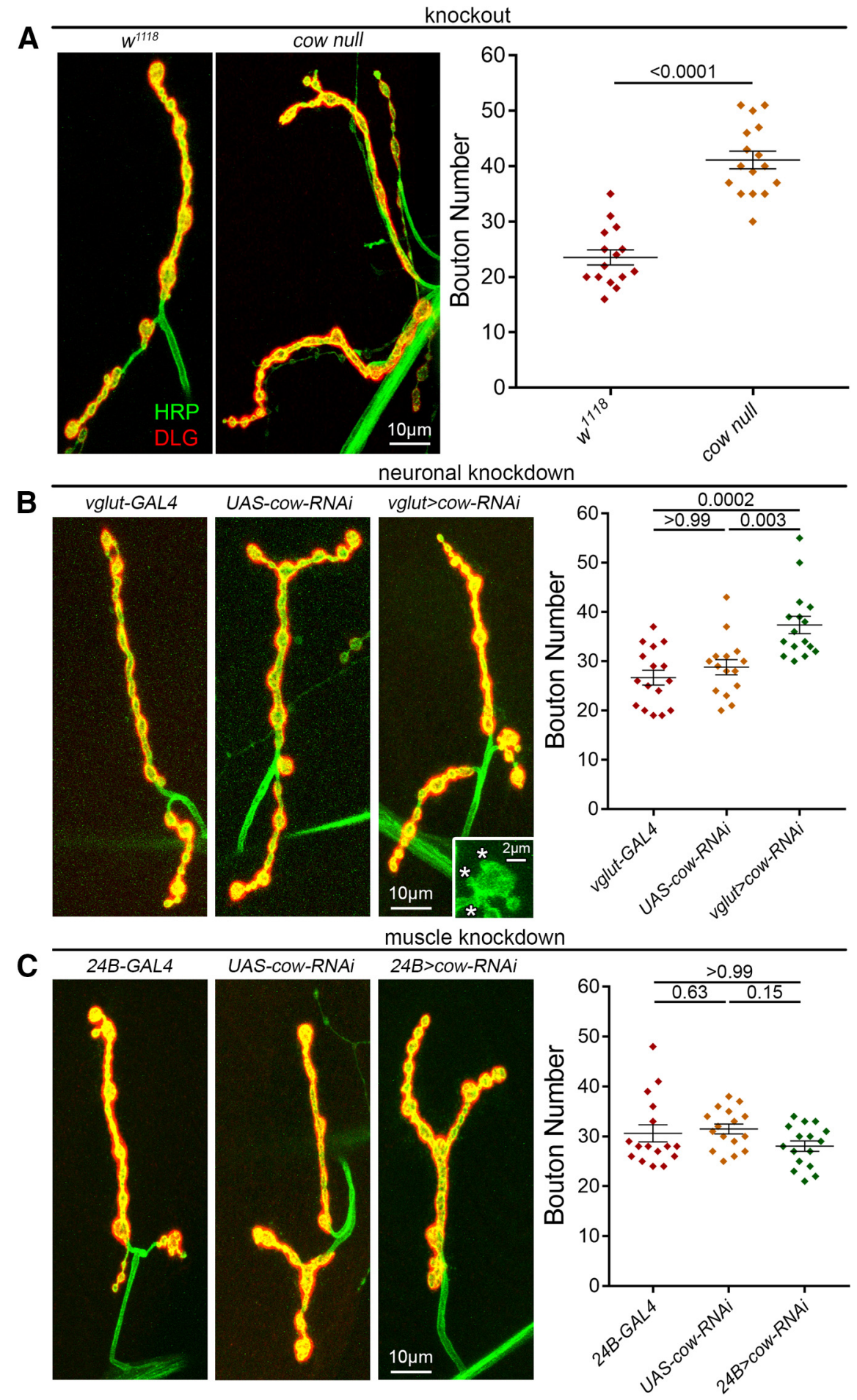

Figure 3. Presynaptically secreted Cow limits NMJ synaptic bouton number. $\boldsymbol{A}$, Confocal images of the muscle 4 NMJ colabeled with anti-HRP (green) to mark the presynaptic membrane and anti-DLG (red) to mark the postsynaptic domain in the genetic background control ( $w^{1118}$, left) and the cow null mutant (cow ${ }^{G D P} / D f$, right). Synaptic bouton number is shown in a scatter plot, with mean \pm SEM. B, Representative confocal NMJ images of motor neuron-targeted Gal4 driver control (vglut-Gal4/+; left), UAS-RNAi transgene control (UAS-cow-RNAi/+, middle) and cow RNAi knockdown (vglut $>$ cow-RNAi, right). Satellite boutons (asterisks) are shown in the inset. Right, Synaptic bouton number is shown in a scatter plot, with mean \pm SEM. C, Representative confocal NMJ images of muscle-targeted Gal4 driver control (24B-Gal4/+, left), UAS-RNAi transgene control (UAS-cow-RNAi/+, middle) and cow RNAi knockdown (24B >cow-RNAi, right). Synaptic bouton number is quantified to the right. The $p$ values are shown for each statistical comparison. 
Table 1: Statistical tests used to analyze data

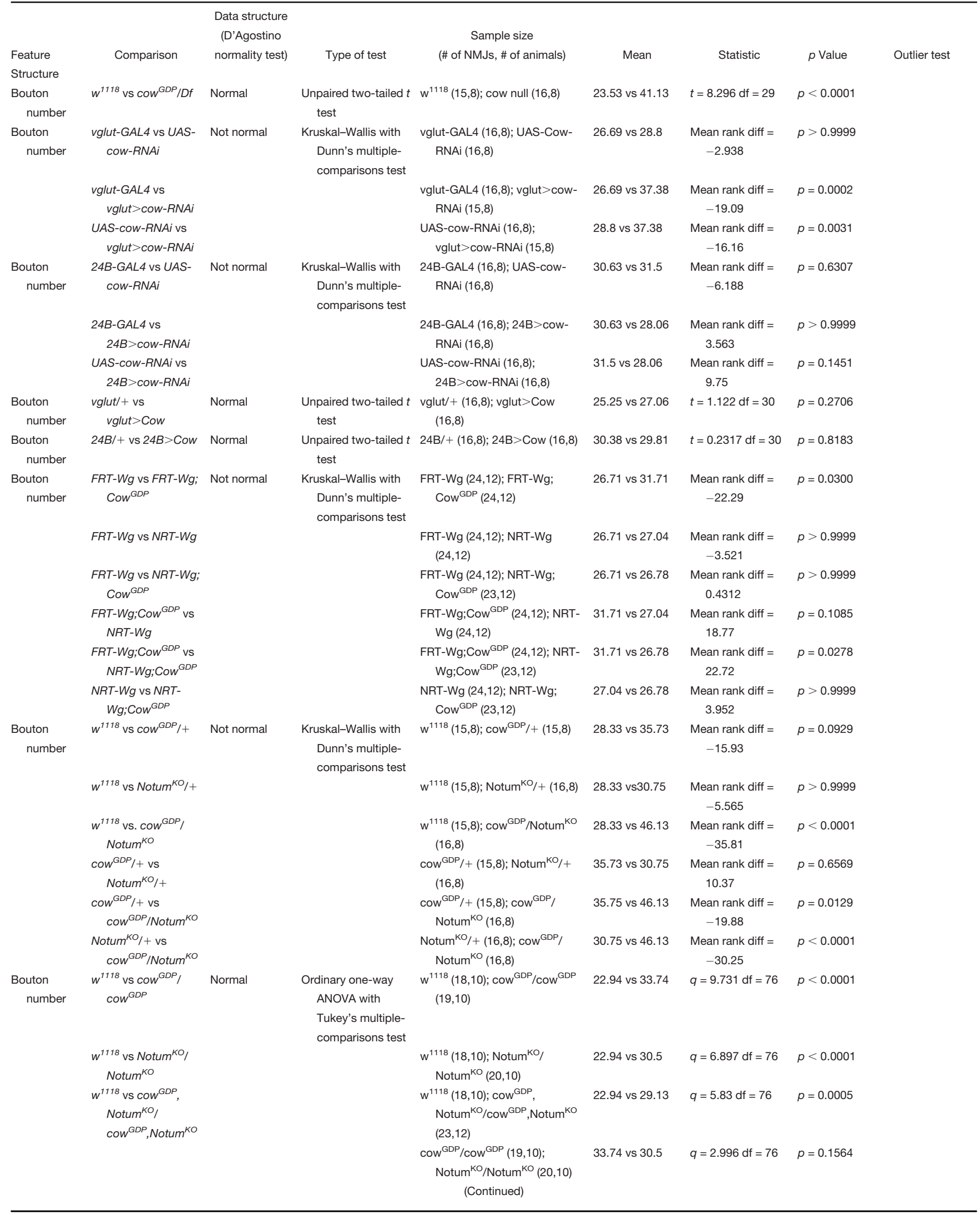


Table 1: Continued

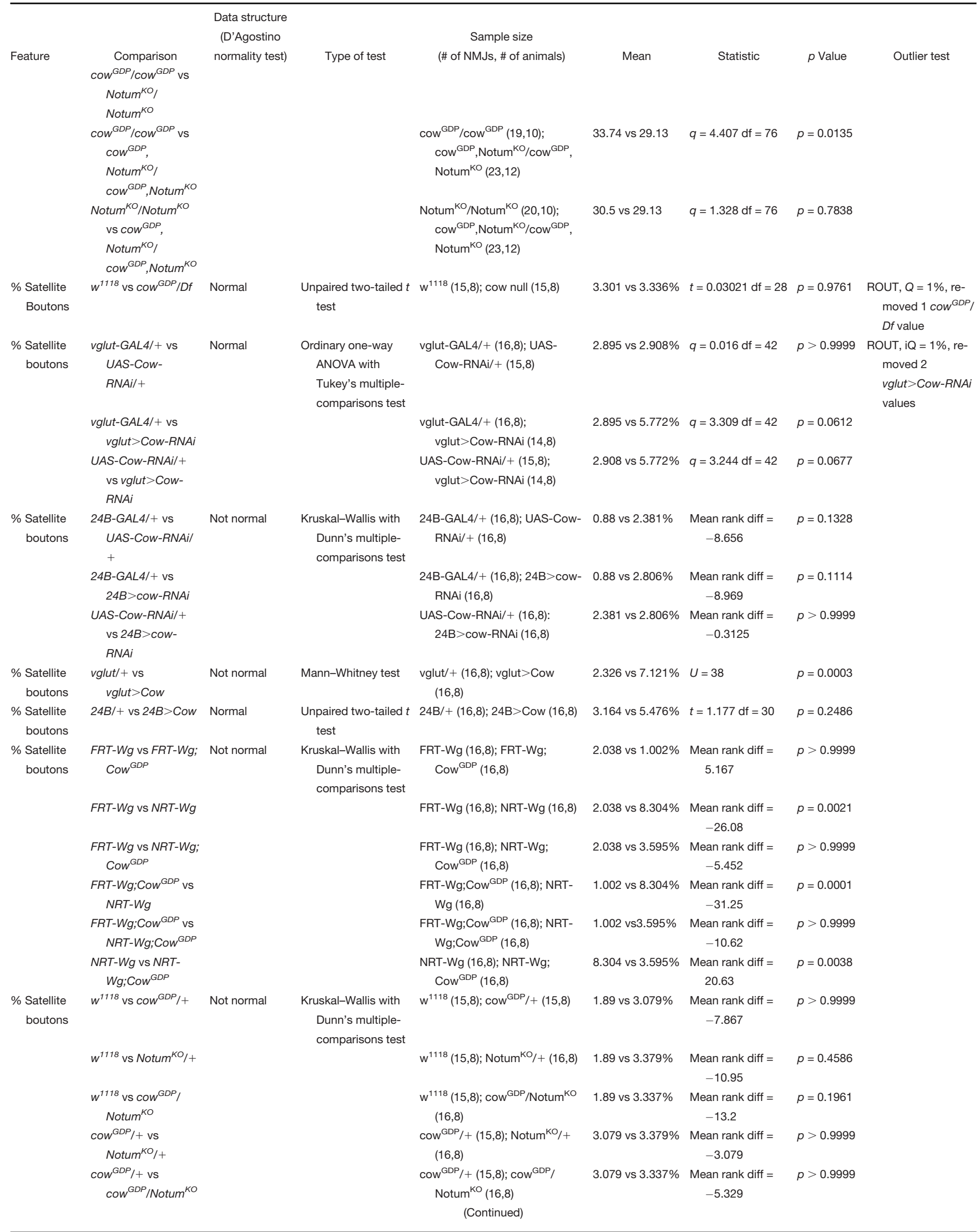


Table 1: Continued

\begin{tabular}{|c|c|c|c|c|c|c|c|c|}
\hline & & Data structure & & & & & & \\
\hline & & (D'Agostino & & Sample size & & & & \\
\hline \multirow[t]{2}{*}{ Feature } & Comparison & normality test) & Type of test & (\# of NMJs, \# of animals) & Mean & Statistic & $p$ Value & Outlier test \\
\hline & $\begin{array}{l}\text { Notum }^{K O} /+ \text { vs } \\
\operatorname{cow}^{G D P} / \text { Notum }^{K O}\end{array}$ & & & $\begin{array}{l}\text { Notum } \\
\text { NO/+ }(16,8) ; \text { cow }^{\mathrm{GDP}} / \\
\text { Notum }^{\mathrm{KO}}(16,8)\end{array}$ & 3.379 vs $3.337 \%$ & $\begin{array}{l}\text { Mean rank diff = } \\
-2.25\end{array}$ & $p>0.9999$ & \\
\hline \multirow[t]{6}{*}{$\begin{array}{l}\% \text { Satellite } \\
\text { boutons }\end{array}$} & $\begin{array}{c}w^{1118} \text { vs } \operatorname{cow}^{G D P} / \\
\operatorname{cow}^{G D P}\end{array}$ & Not normal & $\begin{array}{l}\text { Kruskal-Wallis with } \\
\text { Dunn's multiple- } \\
\text { comparisons test }\end{array}$ & $\begin{array}{l}\mathrm{w}^{1118}(18,10) ; \mathrm{cow}^{\mathrm{GDP}} / \mathrm{cow}^{\mathrm{GDP}} \\
(19,10)\end{array}$ & 1.904 vs $1.623 \%$ & $\begin{array}{l}\text { Mean rank diff }= \\
2.006\end{array}$ & $p>0.9999$ & \\
\hline & $\begin{array}{l}w^{1118} \text { vs Notum }^{K O} / \\
\text { Notum }^{\text {KO }}\end{array}$ & & & $\begin{array}{l}\mathrm{w}^{1118}(18,10) ; \text { Notum }^{\mathrm{KO} /} \\
\text { Notum }^{\mathrm{KO}}(20,10)\end{array}$ & 1.904 vs $2.443 \%$ & $\begin{array}{l}\text { Mean rank diff }= \\
-1.989\end{array}$ & $p>0.9999$ & \\
\hline & $\begin{array}{l}w^{1118} \text { vs } \operatorname{cow}^{G D P}, \\
\text { Notum }^{K O} / \\
\operatorname{cow}^{G D P}, \text { Notum }^{K O}\end{array}$ & & & $\begin{array}{l}\mathrm{w}^{1118}(18,10) ; \operatorname{cow}^{\mathrm{GDP}}, \\
\text { Notum }^{\mathrm{KO}} / \mathrm{cow}^{\mathrm{GDP}}, \text { Notum }^{\mathrm{KO}} \\
(23,12)\end{array}$ & $\begin{array}{l}1.904 \text { vs } \\
0.5223 \%\end{array}$ & $\begin{array}{l}\text { Mean rank diff = } \\
\quad 9.155\end{array}$ & $p=0.7029$ & \\
\hline & $\begin{array}{l}\operatorname{cow}^{G D P} / \operatorname{cow}^{G D P} \text { vs } \\
\text { Notum }^{K O} / \\
\text { Notum }^{K O}\end{array}$ & & & $\begin{array}{l}\operatorname{cow}^{\mathrm{GDP}} / \mathrm{cow}^{\mathrm{GDP}}(19,10) ; \\
\text { Notum }^{\mathrm{KO}} / \operatorname{Notum}^{\mathrm{KO}}(20,10)\end{array}$ & 1.623 vs $2.443 \%$ & $\begin{array}{l}\text { Mean rank diff = } \\
-3.995\end{array}$ & $p>0.9999$ & \\
\hline & $\begin{array}{l}\operatorname{cow}^{G D P} / \text { cow }^{G D P} \text { vs } \\
\operatorname{cow}^{G D P}, \\
\text { Notum }^{K O} / \\
\text { cow }^{G D P}, \text { Notum }^{K O}\end{array}$ & & & $\begin{array}{l}\operatorname{cow}^{\mathrm{GDP}} / \operatorname{cow}^{\mathrm{GDP}}(19,10) ; \\
\operatorname{cow}^{\mathrm{GDP}}, \text { Notum }^{\mathrm{KO}} / \mathrm{cow}^{\mathrm{GDP}}, \\
\text { Notum }^{\mathrm{KO}}(23,12)\end{array}$ & $\begin{array}{l}1.623 \text { vs } \\
0.5223 \%\end{array}$ & $\begin{array}{l}\text { Mean rank diff }= \\
7.149\end{array}$ & $p>0.9999$ & \\
\hline & $\begin{array}{l}\text { Notum }^{K O} / \text { Notum }^{K O} \\
\text { vs cow } \\
\text { GDP, } \\
\text { Notum }^{K O} \text {, } \\
\text { cow }^{G D P}, \text { Notum }^{K O}\end{array}$ & & & $\begin{array}{l}\text { Notum }^{\mathrm{KO}} / \text { Notum }^{\mathrm{KO}}(20,10) ; \\
\operatorname{cow}^{\mathrm{GDP}}, \text { Notum }^{\mathrm{KO}} / \mathrm{cow}^{\mathrm{GDP}}, \\
\text { Notum }^{\mathrm{KO}}(23,12)\end{array}$ & $\begin{array}{l}2.443 \text { vs } \\
0.5223 \%\end{array}$ & $\begin{array}{l}\text { Mean rank diff }= \\
11.14\end{array}$ & $p=0.2978$ & \\
\hline \multicolumn{9}{|l|}{ Expression } \\
\hline Cow intensity & $\begin{array}{l}\text { vglut/+ vs } \\
\qquad \text { vglut }>\text { Cow }\end{array}$ & Not normal & Mann-Whitney test & $\begin{array}{l}\text { vglut/+ }(16,8) ; \text { vglut }>\text { Cow } \\
\quad(16,8)\end{array}$ & 1 vs 3.035 & $U=0$ & $p<0.0001$ & \\
\hline Cow intensity & $24 B /+$ vs $24 B>$ Cow & Not normal & Mann-Whitney test & $24 \mathrm{~B} /+(16,8) ; 24 \mathrm{~B}>\operatorname{Cow}(16,8)$ & 1 vs 3.907 & $U=0$ & $p<0.0001$ & \\
\hline Wg intensity & $\begin{array}{l}\text { vglut } /+ \text { vs } \\
\qquad \text { vglut }>\text { Cow }\end{array}$ & Not normal & Mann-Whitney test & $\begin{array}{l}\text { vglut/+ }(16,8) ; \text { vglut }>\text { Cow } \\
\quad(16,8)\end{array}$ & 1 vs 0.6731 & $U=46$ & $p=0.0014$ & \\
\hline Wg intensity & $24 B /+$ vs $24 B>$ Cow & Normal & $\begin{array}{l}\text { Unpaired two-tailed } t \\
\text { test }\end{array}$ & $24 \mathrm{~B} /+(16,8) ; 24 \mathrm{~B}>\operatorname{Cow}(16,8)$ & 1 vs 1.518 & $t=3.266 \mathrm{df}=30$ & $p=0.0027$ & \\
\hline \multirow[t]{7}{*}{ Wg intensity } & $w^{1118}$ vs $\operatorname{cow}^{G D P} /+$ & Normal & $\begin{array}{l}\text { Ordinary one-way } \\
\text { ANOVA with } \\
\text { Tukey's multiple- } \\
\text { comparisons test }\end{array}$ & $\mathrm{w}^{1118}(15,8) ; \operatorname{cow}^{\mathrm{GDP}} /+(15,8)$ & 1 vs 0.885 & $q=1.328 \mathrm{df}=56$ & $p=0.7840$ & \\
\hline & $w^{1118}$ vs Notum ${ }^{K O} /+$ & & & $\mathrm{w}^{1118}(15,8) ;$ Notum$^{\mathrm{KO}} /+(15,8)$ & 1 vs 1.095 & $q=1.094 \mathrm{df}=56$ & $p=0.8660$ & \\
\hline & $w^{1118}$ vs cow $w^{G D P} /$ & & & $\mathrm{w}^{1118}(15,8) ;$ cow $^{\mathrm{GDP}} /$ Notum $^{\mathrm{KO}}$ & 1 vs 0.9014 & $q=1.139 \mathrm{df}=56$ & $p=0.8515$ & \\
\hline & Notum ${ }^{K O}$ & & & $(15,8)$ & & & & \\
\hline & $\begin{array}{l}\operatorname{cow}^{G D P} /+ \text { vs } \\
\text { Notum } \\
\text { KO } /+\end{array}$ & & & $\begin{array}{l}\operatorname{cow}^{\mathrm{GDP}} /+(15,8) ; \text { Notum }^{\mathrm{KO}} /+ \\
\quad(15,8)\end{array}$ & 0.885 vs 1.095 & $q=2.422 \mathrm{df}=56$ & $p=0.3268$ & \\
\hline & $\begin{array}{l}\operatorname{cow}^{G D P} /+ \text { vs } \\
\operatorname{cow}^{G D P} / \text { Notum }^{K O}\end{array}$ & & & $\begin{array}{l}\operatorname{cow}^{\mathrm{GDP} /+}(15,8) ; \operatorname{cow}^{\mathrm{GDP}} / \\
\operatorname{Notum}^{\mathrm{KO}}(15,8)\end{array}$ & 0.885 vs 0.9014 & $q=0.1886 \mathrm{df}=56$ & $p=0.9991$ & \\
\hline & $\begin{array}{l}\text { Notum }{ }^{K O} /+ \text { vs } \\
\operatorname{cow}^{G D P} / \text { Notum }^{K O}\end{array}$ & & & $\begin{array}{l}\text { Notum } \\
\text { Notum }^{\mathrm{KO}}(15,8)\end{array}$ & 1.095 vs 0.9014 & $q=2.234 \mathrm{df}=56$ & $p=0.3985$ & \\
\hline $\begin{array}{l}\text { Brp punctae } \\
\text { number }\end{array}$ & $w^{1118}$ vs cow ${ }^{G D P}$ & Normal & $\begin{array}{l}\text { Unpaired two-tailed } t \\
\text { test }\end{array}$ & $w^{1118}(15,8) ; \operatorname{cow}^{\mathrm{GDP}}(15,8)$ & 193.1 vs 284.8 & $t=6.152 \mathrm{df}=28$ & $p<0.0001$ & \\
\hline $\begin{array}{l}\text { Brp punctae } \\
\quad \text { Volume }\end{array}$ & $w^{1118}$ vs cow ${ }^{G D P}$ & Normal & $\begin{array}{l}\text { Unpaired two-tailed } t \\
\text { test }\end{array}$ & $w^{1118}(15,8) ; \operatorname{cow}^{\mathrm{GDP}}(15,8)$ & $\begin{array}{l}0.8576 \text { vs } \\
0.7164 \mu \mathrm{m}^{3}\end{array}$ & $t=3.429 \mathrm{df}=28$ & $p=0.0019$ & $\begin{array}{l}\text { ROUT, } Q=1 \% \text {, re- } \\
\text { moved } 1 \text { cow }^{G D P} \\
\text { value }\end{array}$ \\
\hline $\begin{array}{l}\text { Brp punctae } \\
\text { number }\end{array}$ & $w^{1118}$ vs cow ${ }^{G D P}$ & Normal & $\begin{array}{l}\text { Unpaired two-tailed } t \\
\text { test }\end{array}$ & $w^{1118}(11,8) ; \operatorname{cow}^{\mathrm{GDP}}(10,8)$ & 298.6 vs 387.9 & $t=3.598 \mathrm{df}=19$ & $p=0.0019$ & \\
\hline $\begin{array}{l}\text { GluR cluster } \\
\text { number }\end{array}$ & $w^{1118}$ vs cow ${ }^{G D P}$ & Normal & $\begin{array}{l}\text { Unpaired two-tailed } t \\
\text { test }\end{array}$ & $\mathrm{w}^{1118}(11,8) ; \operatorname{cow}^{\mathrm{GDP}}(9,6)$ & 382 vs 542.8 & $t=4.353 \mathrm{df}=18$ & $p=0.0004$ & \\
\hline \multicolumn{9}{|l|}{ Function } \\
\hline \multirow[t]{4}{*}{$\begin{array}{l}\text { EJC } \\
\text { amplitude }\end{array}$} & $w^{1118}$ vs cow ${ }^{G D P}$ & Normal & $\begin{array}{l}\text { Ordinary one-way } \\
\text { ANOVA with } \\
\text { Tukey's multiple- } \\
\text { comparisons test }\end{array}$ & $\mathrm{w}^{1118}(26,20) ; \operatorname{cow}^{\mathrm{GDP}}(20,18)$ & $\begin{array}{l}171.6 \text { vs } 212.1 \\
n \mathrm{nA}\end{array}$ & $q=3.868 d f=53$ & $p=0.0227$ & $\begin{array}{l}\text { ROUT, } Q=1 \% \text {, re- } \\
\text { moved } 1 \text { cow }^{G D P} \\
\text { value }\end{array}$ \\
\hline & $w^{1118}$ vs cow $w^{G D P} / D f$ & & & $\mathrm{w}^{1118}(26,20) ; \operatorname{cow}^{\mathrm{GDP}} / \mathrm{Df}(10,9)$ & $\begin{array}{l}171.6 \text { vs } 254.2 \\
n A\end{array}$ & $q=4.197 \mathrm{df}=53$ & $p=0.0123$ & \\
\hline & $\begin{array}{l}\operatorname{cow}^{G D P} \text { vs } c o w^{G D P /} \\
\quad D f\end{array}$ & & & $\begin{array}{l}\operatorname{cow}^{\mathrm{GDP}}(20,18) ; \operatorname{cow}^{\mathrm{GDP}} / \mathrm{Df} \\
\quad(10,9)\end{array}$ & $\begin{array}{l}212.1 \text { vs } 254.2 \\
n \mathrm{nA}\end{array}$ & $q=1.063 \mathrm{df}=53$ & $p=0.7341$ & \\
\hline & & & & (Continued) & & & & \\
\hline
\end{tabular}


Table 1: Continued

\begin{tabular}{|c|c|c|c|c|c|c|c|c|}
\hline Feature & Comparison & $\begin{array}{l}\text { Data structure } \\
\text { (D'Agostino } \\
\text { normality test) }\end{array}$ & Type of test & $\begin{array}{c}\text { Sample size } \\
\text { (\# of NMJs, \# of animals) }\end{array}$ & Mean & Statistic & $p$ Value & Outlier test \\
\hline \multirow[t]{6}{*}{$\begin{array}{l}\text { EJC } \\
\qquad \text { amplitude }\end{array}$} & $w^{1118} \mathrm{vs} \mathrm{cow}^{\mathrm{GDP} /+}$ & Normal & $\begin{array}{l}\text { Ordinary one-way } \\
\text { ANOVA with } \\
\text { Tukey's multiple- } \\
\text { comparisons test }\end{array}$ & $\mathrm{w}^{1118}(10,6) ; \operatorname{cow}^{\mathrm{GDP}} /+(11,6)$ & $\begin{array}{l}217.2 \text { vs } 234.9 \\
n A\end{array}$ & $q=0.9383 \mathrm{df}=40$ & $p=0.9101$ & \\
\hline & $w^{1118}$ vs notum $^{K O} /+$ & & & $\mathrm{w}^{1118}(10,6) ;$ notum $^{\mathrm{KO} /+}(11,9)$ & $\begin{array}{l}217.2 \text { vs } 214.1 \\
n A\end{array}$ & $q=0.1649 \mathrm{df}=40$ & $p=0.9994$ & \\
\hline & $\begin{array}{l}w^{1118} \text { vs cow }^{G D P /} \\
\text { notum }^{K O}\end{array}$ & & & $\begin{array}{l}\mathrm{w}^{1118}(10,6) ; \text { cow }^{\mathrm{GDP}} / \text { notum }^{\mathrm{KO}} \\
\quad(12,7)\end{array}$ & $\begin{array}{l}217.2 \text { vs } 235.9 \\
n A\end{array}$ & $q=1.009 \mathrm{df}=40$ & $p=0.8911$ & \\
\hline & $\begin{array}{c}\operatorname{cow}^{G D P} /+ \text { vs } \\
\text { notum }^{K O} /+\end{array}$ & & & $\begin{array}{l}\operatorname{cow}^{\mathrm{GDP}} /+(11,6) ; \text { notum }^{\mathrm{KO}} /+ \\
\quad(11,9)\end{array}$ & $\begin{array}{l}234.9 \text { vs } 214.1 \\
n A\end{array}$ & $q=1.13 \mathrm{df}=40$ & $p=0.8543$ & \\
\hline & $\begin{array}{l}\operatorname{cow}^{G D P} /+ \text { vs } \\
\operatorname{cow}^{G D P} / \text { notum }^{K O}\end{array}$ & & & $\begin{array}{l}\operatorname{cow}^{\mathrm{GDP} /+}(11,6) ; \operatorname{cow}^{\mathrm{GDP} /} \\
\text { notum }^{\mathrm{KO}}(12,7)\end{array}$ & $\begin{array}{l}234.9 \text { vs } 235.9 \\
\text { nA }\end{array}$ & $\begin{array}{l}q=0.05304 \mathrm{df}= \\
\quad 40\end{array}$ & $p>0.9999$ & \\
\hline & $\begin{array}{l}\text { notum }^{K O} /+ \text { vs } \\
\operatorname{cow}^{G D P} / \text { notum }^{K O}\end{array}$ & & & $\begin{array}{l}\text { notum }^{\mathrm{KO}} /+(11,9) ; \operatorname{cow}^{\mathrm{GDP} /} \\
\text { notum }^{\mathrm{KO}}(12,7)\end{array}$ & $\begin{array}{l}214.1 \text { vs } 235.9 \\
n A\end{array}$ & $q=1.208 \mathrm{df}=40$ & $p=0.8282$ & \\
\hline \multirow{4}{*}{$\begin{array}{l}\text { mEJC } \\
\text { Frequency }\end{array}$} & $w^{1118}$ vs cow ${ }^{G D P}$ & Normal & Ordinary one-way & $\mathrm{w}^{1118}(22,17) ; \operatorname{cow}^{\mathrm{GDP}}(21,15)$ & 1.396 vs 1.765 & $q=1.419 \mathrm{df}=53$ & $p=0.5780$ & \\
\hline & & & $\begin{array}{l}\text { ANOVA with } \\
\text { Tukey's multiple- } \\
\text { comparisons test }\end{array}$ & & $\mathrm{Hz}$ & & & \\
\hline & $w^{1118}$ vs cow $w^{G D P} / D f$ & & & $\begin{array}{l}\mathrm{w}^{1118}(22,17) ; \operatorname{cow}^{\mathrm{GDP}} / \mathrm{Df} \\
(13,11)\end{array}$ & 1.396 vs $2.41 \mathrm{~Hz}$ & $q=3.406 q=53$ & $p=0.0503$ & \\
\hline & $\begin{array}{l}\operatorname{cow}^{G D P} \text { vs cow }{ }^{G D P /} \\
D f\end{array}$ & & & $\begin{array}{l}\operatorname{cow}^{\mathrm{GDP}}(21,15) ; \mathrm{cow}^{\mathrm{GDP}} / \mathrm{Df} \\
(13,11)\end{array}$ & 1.764 vs $2.41 \mathrm{~Hz}$ & $q=2.15 \mathrm{df}=53$ & $p=0.2897$ & \\
\hline $\begin{array}{l}\text { mEJC } \\
\text { Frequency }\end{array}$ & $\begin{array}{l}\text { vglut-GAL4/+ vs } \\
\quad \text { vglut }>\text { Cow-RNAi }\end{array}$ & Normal & $\begin{array}{l}\text { Unpaired two-tailed } t \\
\text { test }\end{array}$ & $\begin{array}{l}\text { vglut-GAL4/+ }(10,7) \\
\qquad \text { vglut }>\text { Cow-RNAi }(11,7)\end{array}$ & $\begin{array}{l}1.497 \text { vs } 2.449 \\
\mathrm{~Hz}\end{array}$ & $t=2.142 \mathrm{df}=19$ & $p=0.0454$ & $\begin{array}{c}\text { ROUT, } Q=1 \% \text {, re- } \\
\text { moved } 1 \text { vglut- } \\
\text { GAL4/+ value }\end{array}$ \\
\hline \multirow[t]{3}{*}{$\begin{array}{l}\text { mEJC } \\
\text { amplitude }\end{array}$} & $w^{1118}$ vs $\operatorname{cow}^{G D P}$ & Normal & $\begin{array}{l}\text { Ordinary one-way } \\
\text { ANOVA with } \\
\text { Tukey's multiple- } \\
\text { comparisons test }\end{array}$ & $\mathrm{w}^{1118}(21,16) ; \operatorname{cow}^{\mathrm{GDP}}(21,15)$ & $\begin{array}{l}0.7518 \text { vs } \\
0.8682 \mathrm{nA}\end{array}$ & $q=2.506 \mathrm{df}=52$ & $p=0.1889$ & $\begin{array}{l}\text { ROUT, } Q=1 \% \text {, re- } \\
\text { moved } 1 w^{1118} \\
\text { value }\end{array}$ \\
\hline & $w^{1118}$ vs cow $w^{G D P} / D f$ & & & $\begin{array}{l}\mathrm{w}^{1118}(21,16) ; \operatorname{cow}^{\mathrm{GDP}} / \mathrm{Df} \\
(13,11)\end{array}$ & $\begin{array}{l}0.7518 \text { vs } \\
0.7165 \mathrm{nA}\end{array}$ & $q=0.6647 \mathrm{df}=52$ & $p=0.8856$ & \\
\hline & $\begin{array}{l}\operatorname{cow}^{G D P} \text { vs cow }{ }^{G D P} / \\
D f\end{array}$ & & & $\begin{array}{l}\operatorname{cow}^{\mathrm{GDP}}(21,15) ; \mathrm{cow}^{\mathrm{GDP}} / \mathrm{Df} \\
(13,11)\end{array}$ & $\begin{array}{l}0.8682 \text { vs } \\
0.7165 \mathrm{nA}\end{array}$ & $q=2.857 \mathrm{df}=52$ & $p=0.1175$ & \\
\hline $\begin{array}{l}\text { mEJC } \\
\text { amplitude }\end{array}$ & $\begin{array}{l}\text { vglut-GAL4/+ vs } \\
\qquad \text { vglut }>\text { Cow-RNAi }\end{array}$ & Normal & $\begin{array}{l}\text { Unpaired two-tailed } t \\
\text { test }\end{array}$ & $\begin{array}{l}\text { vglut-GAL4/+ }(11,7) \\
\qquad \text { vglut }>\text { Cow-RNAi }(11,7)\end{array}$ & $\begin{array}{l}0.8015 \text { vs } \\
0.8446 \mathrm{nA}\end{array}$ & $t=0.8011 \mathrm{df}=20$ & $p=0.4325$ & \\
\hline Frequency & $\begin{array}{l}\text { vglut/+ vs } \\
\qquad v g / u t>R N A i\end{array}$ & $\begin{array}{l}\text { Not normal } \\
\text { (Shapiro- } \\
\text { Wilk normal- } \\
\text { ity test per- } \\
\text { formed be- } \\
\text { cause N too } \\
\text { small) }\end{array}$ & Mann-Whitney test & vglut/ $+(7,4) ;$ vglut $>$ RNAi $(6,3)$ & $\begin{array}{c}1.617 \text { vs } 2.977 \\
\mathrm{~Hz} / \mu \mathrm{m}^{2}\end{array}$ & $U=7$ & $p=0.0513$ & \\
\hline Mean $\Delta F / F_{0}$ & $\begin{array}{l}\text { vglut/+ vs } \\
\quad v g / u t>R N A i\end{array}$ & $\begin{array}{l}\text { Normal } \\
\text { (Shapiro- } \\
\text { Wilk normal- } \\
\text { ity test per- } \\
\text { formed be- } \\
\text { cause } \mathrm{N} \text { too } \\
\text { small) }\end{array}$ & $\begin{array}{l}\text { Unpaired two-tailed } t \\
\text { test }\end{array}$ & vglut/ + $(8,4) ;$ vglut $>\operatorname{RNAi}(5,3)$ & $\begin{array}{l}0.7912 \text { vs } 1.058 \\
\quad \Delta \mathrm{F} / \mathrm{F}_{0}\end{array}$ & $t=3.013 \mathrm{df}=11$ & $p=0.0118$ & \\
\hline
\end{tabular}

$1.5 \pm 0.33 \mathrm{~Hz}$ vs vglut $>$ Cow $-R N A i, 2.45 \pm 0.3 ; p=0.045)$, but not amplitude (vglut-Gal4/+, $0.8 \pm 0.03 \mathrm{nA}$ vs vglut $>$ Cow-RNAi, $0.85 \pm 0.42 ; p=0.4325)$. SynapGCaMP imaging also shows increased fusion frequency in type lb boutons (Fig. 5E). In quantal imaging measurements, spontaneous fusion frequency increases (vglut-Gal $4 /+, 1.62 \pm 0.47 \mathrm{~Hz} /$ $\mu \mathrm{m}^{2}$ vs vglut $>$ cow-RNAi, $2.98 \pm 0.36 ; p=0.051$; Fig. $5 F$, left). Interestingly, event magnitude also significantly increases (vglut-Gal4/+, $0.79 \pm 0.04 \Delta F / F_{0}$ vs vglut $>$ cow$R N A i, 1.06 \pm 0.09 ; p=0.012$; Fig. $5 F$, right). These results demonstrate that Cow limits evoked neurotransmission strength and suggest that neuronally secreted Cow regulates synaptic vesicle fusion at the presynaptic active zone.

\section{Cow restricts presynaptic active zone and glutamatergic synapse formation}

We next used imaging to assay presynaptic and postsynaptic molecular components of the synapse to test the hypothesis of increased NMJ synapse number in cow mutants. The presynaptic AZ is the specialized site of SV 

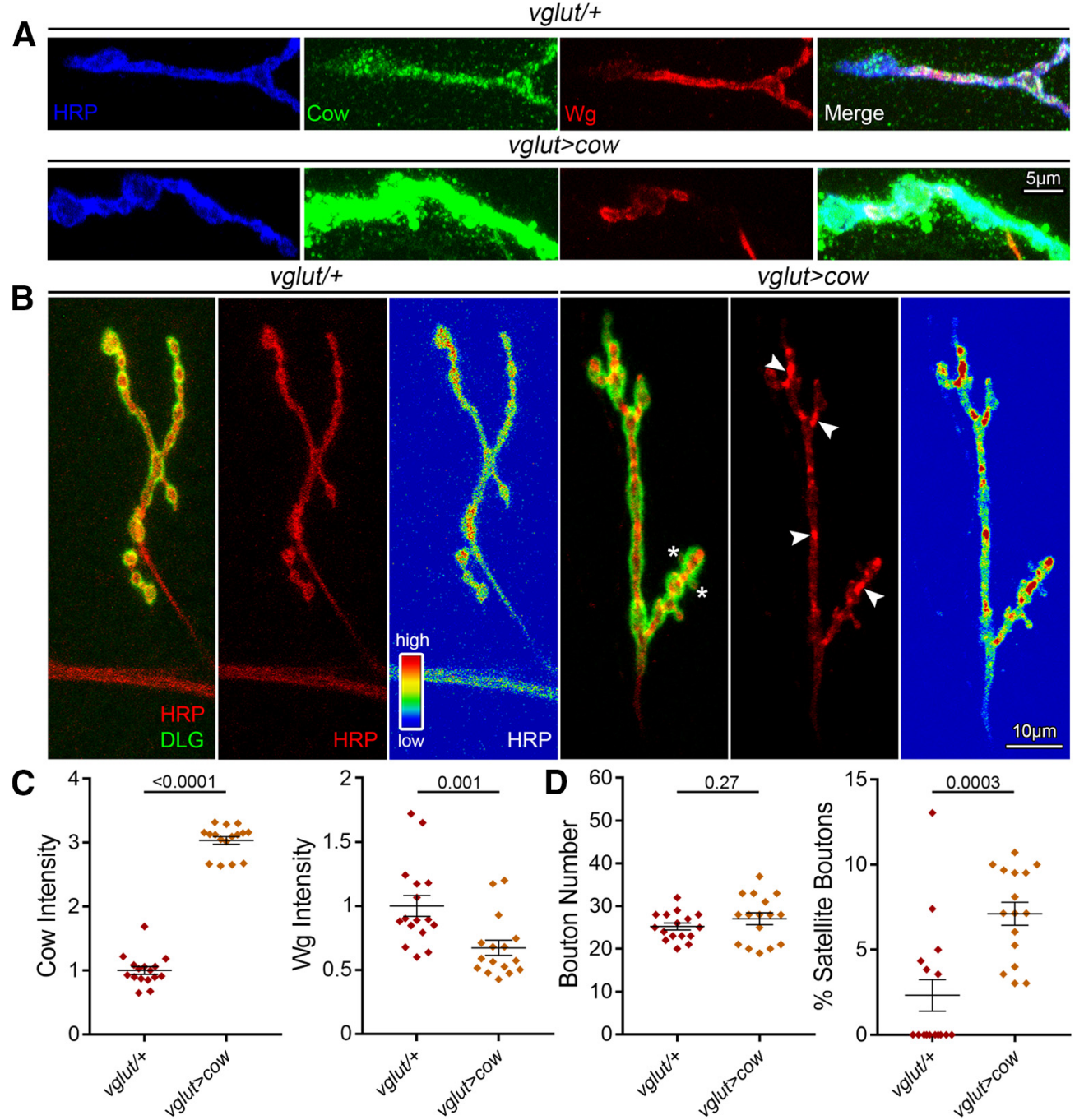

Figure 4. Presynaptic Cow elevation decreases $\mathrm{Wg}$ and increases satellite boutons. $\boldsymbol{A}$, Confocal images of NMJ boutons triple labeled with anti-HRP (blue), anti-Cow (green), and anti-Wg (red), and merged (far right) comparing transgenic controls (vglut-Ga/4/+) to motor neuron Cow overexpression condition (vglut $>$ cow). Labeling was done in the absence of detergent to reveal only secreted Cow and Wg. $\boldsymbol{B}$, Representative muscle $4 \mathrm{NMJ}$ images colabeled for presynaptic HRP (red) and postsynaptic DLG (green) comparing controls (vglut$\mathrm{Gal} / \mathrm{l}+$ ) to neuronal Cow overexpression (vglut $>$ cow). Asterisks indicate satellite boutons. The second panel shows HRP alone with arrows indicating distinct spots of HRP accumulation, and the third panel shows HRP expression heatmap. $\boldsymbol{C}$, Quantification of confocal fluorescence intensity for Cow (left) and $\mathrm{Wg}$ (right) in the two conditions shown in a scatter plot, with mean \pm SEM. $\boldsymbol{D}$, Quantification of synaptic bouton number (left) and the percentage of satellite boutons (right) in transgenic controls versus cow neuronal overexpression shown in a scatter plot, with mean \pm SEM. $p$ Values are shown for each statistical comparison.

fusion that mediates the release of the glutamate neurotransmitter. Brp tethers both the voltage-gated $\mathrm{Ca}^{2+}$ channels and SVs to the $A Z$, and is the best $A Z$ marker (Hallermann et al., 2010). Each AZ directly apposes a postsynaptic GluR cluster to mediate fast neurotransmission (Schuster et al., 1991). We used colabeling with both anti-Brp (Wagh et al., 2006) and anti-GluRIIC (aka GluRIII; Marrus et al., 2004) to compare cow null mutants to $w^{1118}$ genetic background controls (Fig. 6). Brp AZ punctae occur much more often in cow null NMJs (Fig. $6 A$ ), but are consistently smaller in volume (Fig. 6B). In quantified measurements, the number of Brp AZ punctae per NMJ is significantly increased in the cow null mutants compared with matched controls $\left(w^{1118}, 193.1 \pm 10.55\right.$ vs cow ${ }^{G D P}$,
$284.8 \pm 10.54 ; p<0.0001$; Fig. $6 A$, right), but the average volume of the Brp AZ synaptic punctae is significantly decreased in the mutants $\left(w^{1118}, 0.86 \pm 0.033 \mu \mathrm{m}^{3}\right.$ vs cow $^{G D P}, 0.72 \pm 0.025 ; p=0.0019$; Fig. $6 B$, right). This is consistent with a previous report also showing a reciprocal relationship between Brp AZ punctae number and volume (Graf et al., 2009).

Brp AZ punctae are precisely juxtaposed to GluR clusters in a functional synapse (Menon et al., 2013). For better resolution to image postsynaptic GluR clusters and quantify the synaptic apposition, SIM was used (Gustafsson, 2000). To compare with previous LSM, Brp AZs were first measured to find a consistent increase in the cow null mutants, but with larger punctae numbers, 

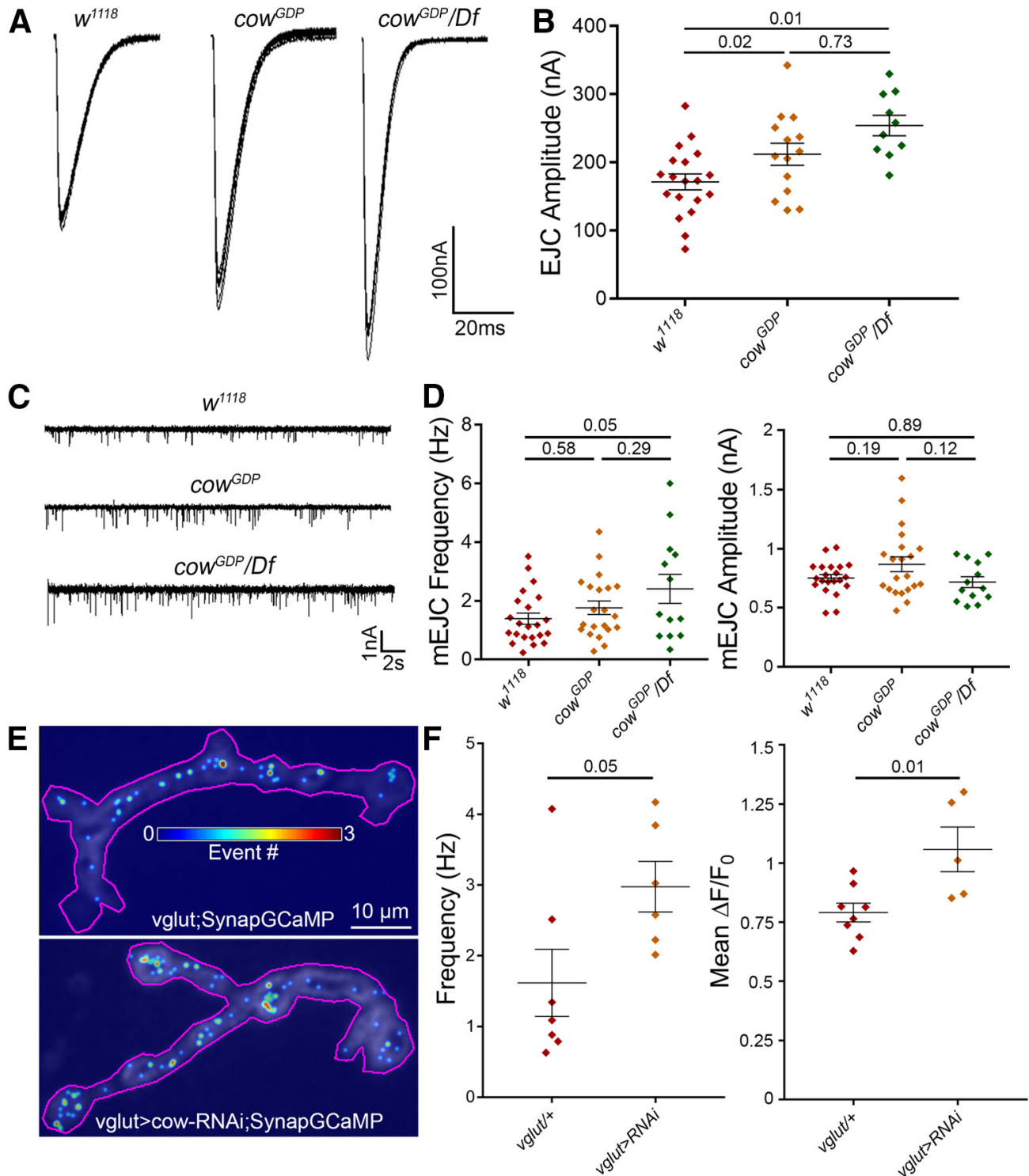

Figure 5. Presynaptic Cow limits synaptic vesicle fusion for NMJ neurotransmission. $\boldsymbol{A}$, Representative motor nerve stimulation-

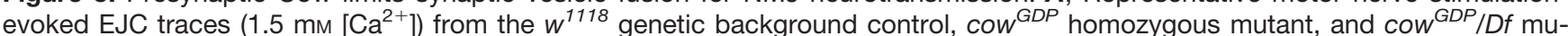
tant. B, Quantification of EJC amplitudes in the three genotypes shown in a scatter plot, with mean \pm SEM. $\boldsymbol{C}$, Representative mEJC recording traces from the same genotypes. $\boldsymbol{D}$, Quantification of mEJC frequency (left) and amplitude (right) from the three genotypes. $\boldsymbol{E}$, Representative probability maps (30 s) of SynapGCaMP imaging of mEJC events in motor neuron-targeted Gal4 driver control (vglut-Gal4/+, top) and cow RNAi knockdown (vglut>cow-RNAi, bottom), indicating mEJC location (dot) and frequency (color; see scale inset). $\boldsymbol{F}$, Quantification of SynapGCaMP event frequency (in $\mathrm{Hz} / \mu \mathrm{m}^{2}$; left) and fluorescence intensity $\left(\Delta F / F_{0}\right.$; right) shown in scatter plots, with mean \pm SEM. $p$ Values are shown for each statistical comparison.

presumably due to increased resolution $\left(w^{111}, 298.6 \pm\right.$ 17.2 vs cow $^{G D P}, 387.9 \pm 17.86 ; p=0.0019$; Fig. $6 C$ ). There is also a similar increase in GluR clusters $\left(w^{1118}\right.$, $382 \pm 23.21$ vs cow $^{G D P}$, $542.8 \pm 29.41 ; p=0.0004$; Fig. $6 D$ ). Brp punctae and GluR clusters almost always partner, with rare exceptions seen at a similar frequency in controls and mutants (Fig. 6D). There are more GluR clusters than Brp punctae in both genotypes. The GluR/Brp ratio was measured to test for defects in synaptic apposition. If there is a larger ratio in the mutants compared with controls, this would indicate more GluR clusters without a Brp AZ. Conversely, a smaller ratio would indicate more GluR clusters paired with a presynaptic partner. Quantified measurements show no difference in the GluR/Brp ratio between controls and the cow null mutants $\left(w^{1118}, 1.29 \pm 0.04\right.$ vs cow $^{G D P}, 1.36 \pm 0.05 ; p=0.272$ ). Together, these results demonstrate that Cow limits NMJ synapse formation, which is consistent with strengthened neurotransmission.

\section{Membrane-tethering $\mathrm{Wg}$ prevents cow null defects in NMJ development}

Our starting hypothesis was that Cow regulates Wg by binding the ligand in the extracellular space and carrying 

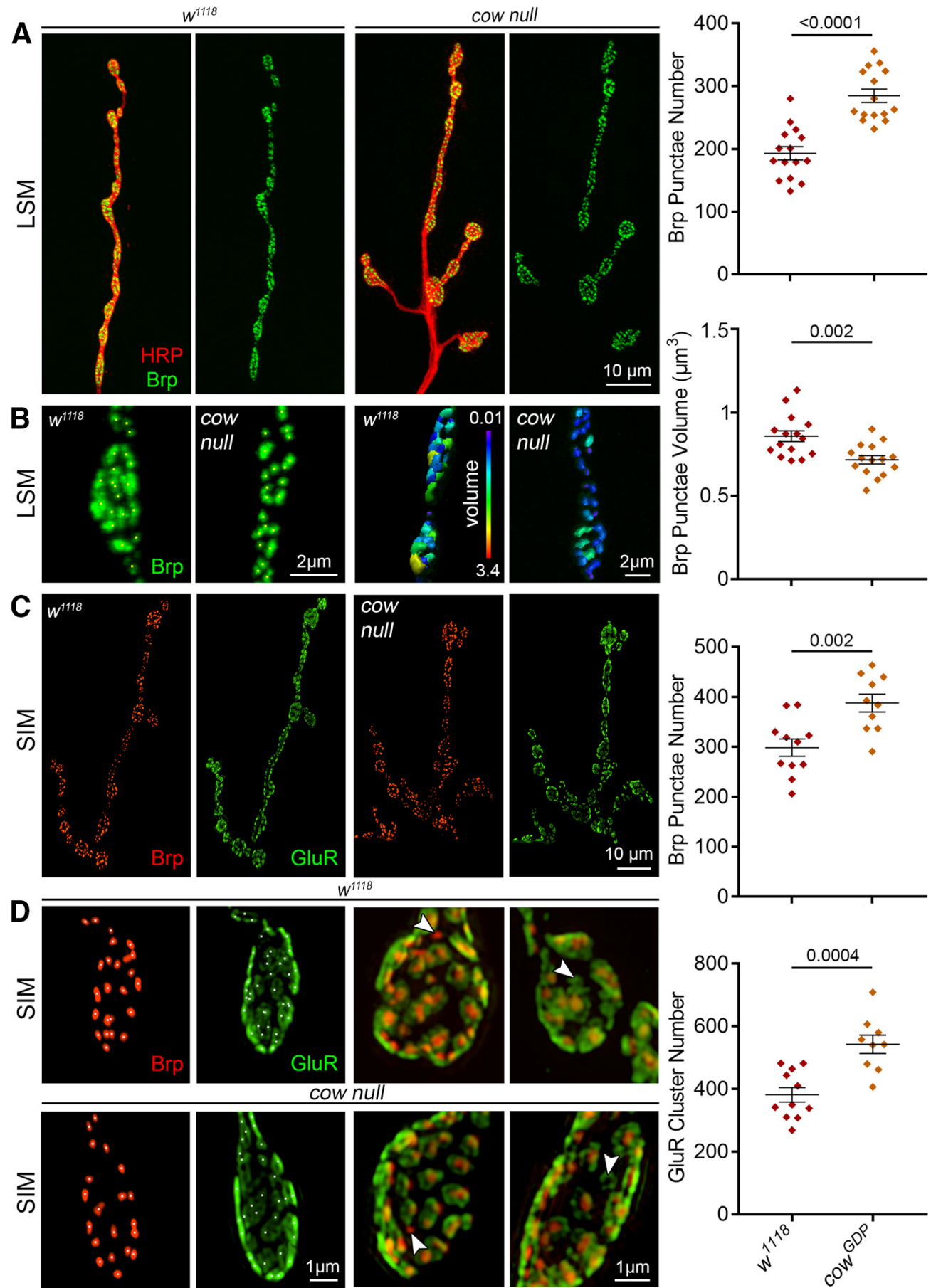

Figure 6. Cow limits presynaptic active zones and glutamatergic synapse number. $\boldsymbol{A}$, Representative muscle 4 NMJ images from confocal LSM of genetic background controls ( $w^{1118}$, left) and cow null mutants (cow ${ }^{G D P}$, right) colabeled for presynaptic membrane marker (HRP, red) and the active zone scaffold Brp (green). Brp alone is shown in right panels and the quantified Brp punctae number is shown to the right. $\boldsymbol{B}$, High-magnification synaptic bouton images with Brp punctate identified using Imaris software (asterisks, left) and volume indicated in a heatmap (scale, $0.01-3.4 \mu \mathrm{m}^{3}$; right). Quantified Brp punctae volume shown to the right. $\boldsymbol{C}$, Representative NMJ images from a SIM of controls $\left(w^{1118}\right)$ and cow nulls $\left(c o w^{G D P}\right)$ colabeled for both presynaptic active zones (Brp, red) and postsynaptic glutamate receptors (GluRIIC, green). The quantified Brp punctae number is shown to the right. $\boldsymbol{D}$, Highmagnification SIM images of juxtaposed Brp punctae and GluR clusters at synapses. Arrowheads indicate Brp or GluR domains without a partner, which are observed at equal frequency in both genotypes. Quantified GluR cluster number is shown to the right. Data shown in scatter plots, with mean \pm SEM. $p$ Values are shown for each statistical comparison. 
it across the synaptic cleft (from neuron to muscle). This hypothesis is based on published work demonstrating that Cow is secreted, directly binds secreted $\mathrm{Wg}$ and acts to mediate intercellular transport (Chang and Sun, 2014). To test this hypothesis, we obtained transgenic lines with the wg gene cut from its native locus via FRT sites and then replaced either without (FRT-wg; transgenic control) or with (NRT-wg) a membrane tether. Importantly, HA-tagged NRT-wg is not secreted from Wg-expressing cells and fails to maintain the expression of long-range Wg targets (Alexandre et al., 2014). We tested whether tethering $\mathrm{Wg}$ to the membrane affects NMJ development. Comparing FRT-wg to NRT-wg, there is increased expression of the $\mathrm{Wg}$ ligand around presynaptic boutons (data not shown). To determine whether tethered $\mathrm{Wg}$ can bind Fz2 receptors, the NMJ bouton number was measured to assess presynaptic $\mathrm{Wg}$ signaling. Next, NRT-wg was combined with the cow null mutant (NRT-wg; cow $^{G D P}$ ) to test the hypothesis that Cow normally acts to regulate secreted $\mathrm{Wg}$ function. If $\mathrm{Wg}$ needs to be secreted and transported dependent on Cow function, then NRT$w g$ and NRT-wg; cow ${ }^{G D P}$ would be predicted to have the same phenotype. Representative images and summarized data are shown in Figure 7.

In comparing the control FRT-wg and tethered NRT$w g$, there is no change in mature NMJ bouton number, but there is a clear increase in the number of immature satellite boutons when $\mathrm{Wg}$ is tethered (Fig. 7A). In quantified measurements, NRT-wg has the same number of NMJ synaptic boutons as the control (FRT-wg, 26.71 \pm 1.04 vs NRT-wg, $27.04 \pm 1.72 ; p=0.999$; Fig. $7 A, B$ ), but a fourfold increase in the percentage of satellite boutons (FRT-wg, $2.04 \pm 0.77 \%$ vs NRT-wg, $8.3 \pm 1.62 ; p=0.0019$; Fig. $7 C$ ). When membrane-tethered $\mathrm{Wg}$ is placed in the cow null background (NRT-wg; cow ${ }^{G D P}$ ), both the mature synaptic bouton number and the percentage of satellite boutons are similar to the FRT-wg control levels (Fig. 7A). In quantified measurements, the mature bouton number is no longer different between the two genotypes ( $F R T$ - $w g$, $26.71 \pm 1.04$ vs NRT-wg; cow ${ }^{G D P}, 26.78 \pm 0.97 ; p=0.999$; Fig. 7B; Table 1, all other comparisons), and the satellite boutons are also restored to near-normal levels (FRT-wg, $2.04 \pm 0.77 \%$ vs NRT-wg; $\operatorname{cow}^{G D P}, 3.60 \pm 1.1 ; p=0.999$; Fig. 7C). Together, these results suggest that Cow facilitates Wg-dependent satellite bouton formation, and that $\mathrm{Wg}$ has to be secreted for Cow to act on it. However, in contrast to the original hypothesis, Cow acts as a negative regulator of secreted $\mathrm{Wg}$ signaling at the $\mathrm{NMJ}$, suggesting that it should interact with other $\mathrm{Wg}$-negative regulators in the extracellular synaptomatrix.

\section{Cow and Notum function together to restrict NMJ growth and bouton formation}

The secreted deacylase Notum has also been recently shown to regulate NMJ synaptic bouton formation via the negative regulation of $\mathrm{Wg}$ trans-synaptic signaling (Kopke et al., 2017). Notum restricts Wnt signaling by cleaving the Wg palmitoyl group that binds to Fz2 receptors (Kakugawa et al., 2015). In notum null mutants, NMJ Wg signaling is elevated both presynaptically and postsynaptically, resulting in increased synaptic bouton number, synapse number, and neurotransmission strength (Kopke et al., 2017). To test the hypothesis that the increased NMJ development in cow null mutants is similarly caused by an increase in Wg trans-synaptic signaling, we performed the genetic test of combining cow and notum null heterozygotes to assay effects on NMJ synaptic bouton development. The failure of mutant alleles at two different loci to complement one another is one method to test for an in vivo interaction of the gene products in a common signaling mechanism (nonallelic noncomplementation; Yook et al., 2001; Hawley and Gilliland, 2006). In this case, the interaction tests the hypothesis that Cow and Notum have closely associated functions in the regulation of Wg synaptic signaling via direct interaction with the $\mathrm{Wg}$ ligand in the extracellular synaptomatrix. We compared bouton formation in genetic background control $\left(w^{1118}\right)$; cow null $\left(\right.$ cow $\left.^{G D P}\right)$, and notum null (notum ${ }^{K O}$ ) homozygotes and heterozygotes; cow/notum trans-heterozygotes; and cow/ notum double null mutant (cow ${ }^{G D P}$, notum ${ }^{K O} /$ cow $^{G D P}$, notum $^{K O}$ ). Representative images and summarized data are shown in Figure 8.

The trans-heterozygote has a clearly expanded NMJ with more synaptic boutons compared with controls, as well as other wg mutant phenotypes such as the appearance of ghost boutons (Fig. $8 A$, inset). Ghost boutons are immature boutons that contain the HRP marker, but do not yet contain the postsynaptic DLG protein (Ataman et al., 2006). The cow (cow ${ }^{G D P} /+$ ) and notum (notum ${ }^{K O} /+$ ) heterozygotes alone are no different from $w^{1118}$ controls and lack synaptic features of impaired $\mathrm{Wg}$ signaling (Fig. $8 A$, Table 1). In quantified measurements, trans-heterozygotes have strongly increased bouton numbers $\left(w^{1118}\right.$,

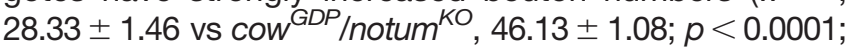
Fig. $8 A$, right; Table 1, all other comparisons). Extracellular Wg labeling without cellular permeabilization in all these genotypes indicates no difference in the $\mathrm{Wg}$ fluorescence intensity (Fig. 8B). In quantified measurements, there is no detectable change in $\mathrm{Wg}$ ligand levels between controls and cow/notum trans-heterozygotes (normalized $w^{1118}, 1.0 \pm 0.09$ vs cow cDP $^{G+}$; notum ${ }^{k O} /+$, $0.9 \pm 0.09 ; p=0.852$; Fig. $8 B$, right; Table 1, all other comparisons). The double null mutants have significantly increased bouton numbers compared with controls but no increase compared with each null alone $\left(w^{1118}\right.$, $22.94 \pm 1.05$ vs cow ${ }^{G D P}$, notum ${ }^{K O} /$ cow $^{G D P}$, notum ${ }^{K O}$, $29.13 \pm 0.97 ; p=0.0005$; Fig. $8 C$, right; Table 1, all other comparisons). Interestingly, trans-heterozygotes show no change in nerve stimulation-evoked EJC recordings (Table 1). These results indicate that Cow and Notum act in the same pathway to restrict $\mathrm{Wg}$ signaling in structural development, and that the level of extracellular Wg ligand alone is not predictive of signaling activity.

\section{Discussion}

The function of signaling ligands in the extracellular space is tightly regulated to ensure coordinated intercellular development, often via glycan-dependent mechanisms (Dani and Broadie, 2012; Parkinson et al., 2013; Shilts and Broadie, 2017). The most recently discovered 


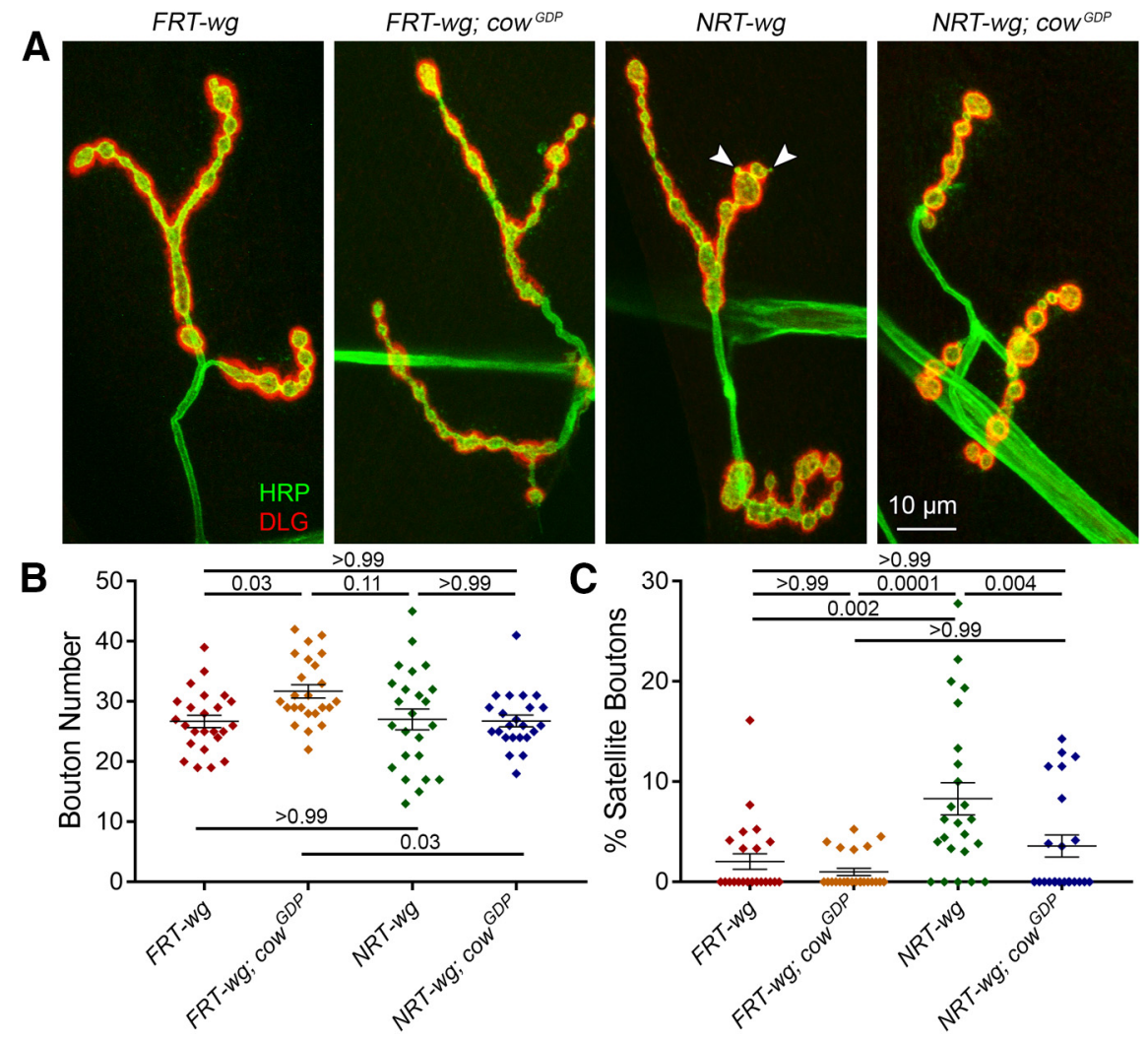

Figure 7. Membrane-tethered Wg prevents cow null defects in bouton formation. $\boldsymbol{A}$, Representative confocal images of muscle 4 NMJs colabeled with presynaptic HRP marker (green) and postsynaptic DLG marker (red) in Wg control (FRT-wg), cow null (FRT$w g$; $\left.\operatorname{cow}^{G D P}\right)$, tethered $\mathrm{Wg}(N R T-w g)$, and tethered $\mathrm{Wg}$ in cow null background (NRT-wg; cow GDP $)$. B, C, Quantification of total NMJ synaptic bouton number $(B)$ and the percentage of satellite boutons $(C)$ in the four genotypes shown in a scatter plot, with mean \pm SEM. $p$ Values are shown for each statistical comparison.

Drosophila HSPG, secreted Cow, was characterized with this role (Chang and Sun, 2014). In the developing wing disk, the Wnt Wg is produced in a stripe of cells at the dor$\mathrm{sal} /$ ventral margin boundary, and acts as an intercellular morphogen through Fz2 receptor signaling (Bhanot et al., 1996; Zecca et al., 1996; Neumann and Cohen, 1997). The glypican HSPGs Dally and Dlp, bound to outer plasma membrane leaflets via GPI anchors, bind $\mathrm{Wg}$ to regulate both ligand distribution and intercellular signaling (Tsuda et al., 1999; Baeg et al., 2001; Dani et al., 2012; Dear et al., 2017). It has been proposed that Dally/DIp HSPGs are involved in the movement of extracellular $\mathrm{Wg}$ to form a morphogen gradient (Han et al., 2005). However, in dally dlp double mutant clones, extracellular $\mathrm{Wg}$ is detected far away from Wg-secreting cells, suggesting that another extracellular factor can transport $\mathrm{Wg}$. Cow was shown to fill this role by binding extracellular $\mathrm{Wg}$ to increase stability and rate of movement from producing to receiving cells (Chang and Sun, 2014). Supporting this model, cow mutants manifest Wg ligand gain-of-function/ overexpression phenotypes for short-range targets, and loss-of-function phenotypes for long-range targets.

At the NMJ, such a long-range Wg morphogen transport function is not seemingly required, except perhaps as a clearance mechanism, but Wg extracellular regulation and short-range $\mathrm{Wg}$ transport to cross the synaptic cleft is critical for NMJ development (Packard et al., 2002; Friedman et al., 2013; Dear et al., 2016; Parkinson et al., 2016). At the forming of NMJ, Wg from neurons and glia signals both presynaptically (neuronal) and postsynaptically (muscle) via Fz2 receptors (Packard et al., 2002; Kerr et al., 2014). In the motor neuron, Wg signaling inhibits the GSK3 $\beta$ homolog Sgg to regulate the MAP1B homolog Futsch to modulate microtubule dynamics controlling NMJ bouton formation (Miech et al., 2008). However, Futsch distribution and microtubule dynamics do not change with elevated Wg signaling (Kopke et al., 2017), so this pathway alone does not explain the increased bouton formation with increased $\mathrm{Wg}$ signaling. In the postsynaptic muscle, Wg signaling drives Fz2 endocytosis and $\mathrm{C}$-terminus cleavage, with transport to the nucleus regulating mRNAs involved in synaptogenesis, including postsynaptic GluR distribution (Speese et al., 2012). In wg mutants, GluRs are more diffuse; with clusters irregular in size/shape, increased receptor numbers and a larger postsynaptic volume (Packard et al., 2002; Speese et al., 2012; Kerr et al., 2014). Thus, Wg trans-synaptic signaling controls both NMJ structure and function.

Based on the findings from Chang and Sun (2014), we hypothesized that Cow binds Wg to facilitate the transport across the synapse to Fz2 receptors on the muscle. If this is correct, we would expect a presynaptic Wg OE 


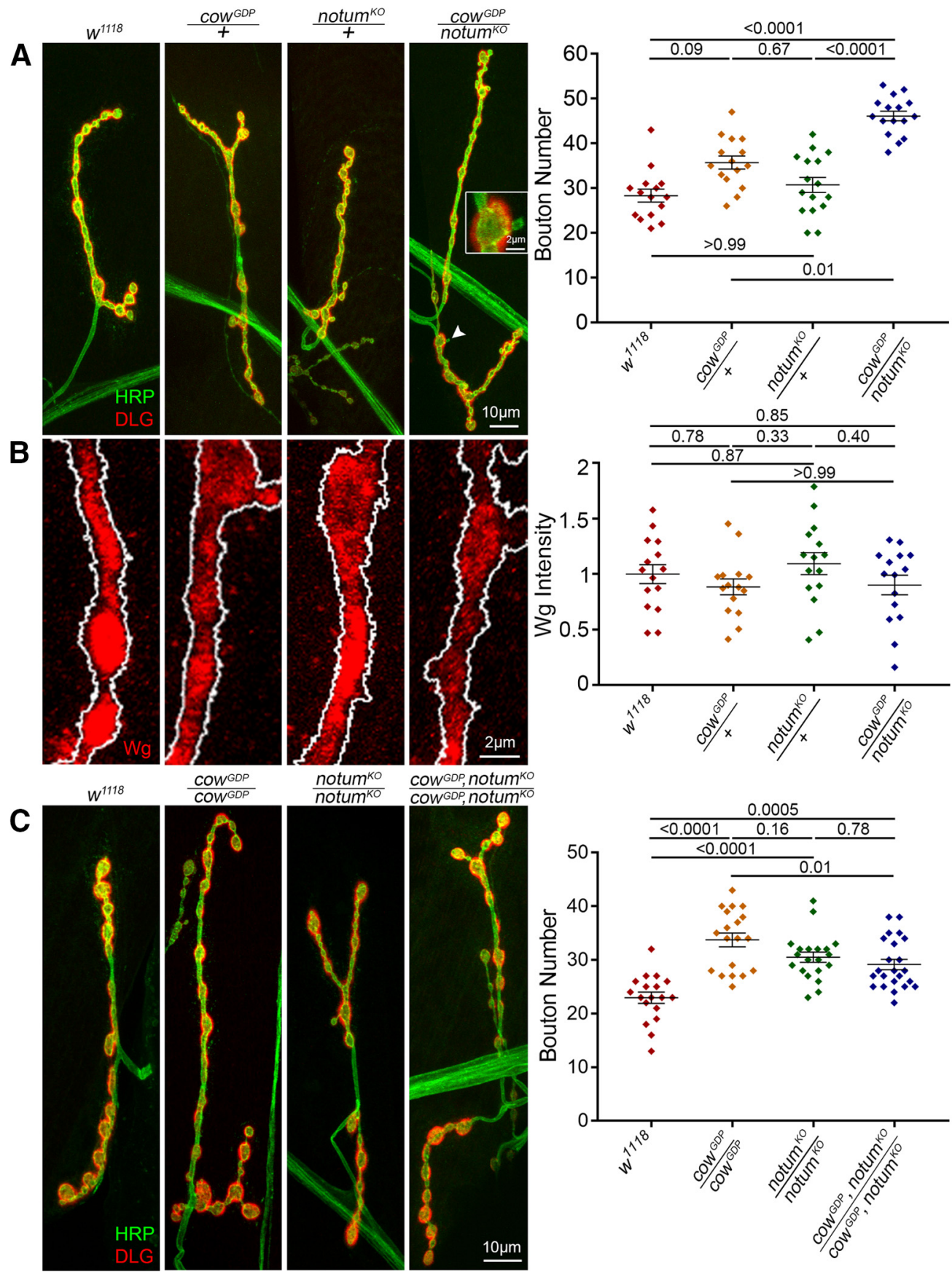

Figure 8. Cow and Notum act in the same Wg pathway to limit NMJ bouton number. $\boldsymbol{A}$, Confocal images of the muscle 4 NMJ colabeled with presynaptic HRP marker (green) and postsynaptic DLG marker (red) in the genetic background control ( $\left.w^{1118}\right)$, cow null heterozygote $\left(\operatorname{cow}^{\mathrm{GDP} /+}\right)$, notum null heterozygote (notum $\mathrm{NO}^{K O}+$ ), and cow/notum transheterozygote $\left(\operatorname{cow}^{G D P} /\right.$ notum $\left.^{K O}\right)$. Quantified bouton number is shown to the right. $\boldsymbol{B}$. High-magnification NMJ confocal images of anti-Wg labeling at synaptic boutons of the same indicated genotypes. The presynaptic HRP marker boundary is outlined in white. Quantified Wg fluorescence intensity is shown to the right, normalized to the background control $\left(w^{1118}\right)$. C. Confocal images of the muscle 4 NMJ colabeled with presynaptic HRP marker (green) and postsynaptic DLG marker (red) in the genetic background control $\left(w^{1118}\right)$, cow null (cow ${ }^{G D P} /$ cow $\left.^{G D P}\right)$, notum null (notum $\mathrm{KO}_{\text {notum }}{ }^{K O}$ ), and cow/notum double null (cow ${ }^{G D P}$, notum ${ }^{K O} /$ cow $^{G D P}$, notum ${ }^{K O}$ ). Quantified bouton number is shown to the right. Data shown in scatter plots, with mean \pm SEM. $p$ Values are shown for each statistical comparison.

phenotype in the absence of Cow (Wg buildup at the source), and a postsynaptic Wg decrease/loss phenotype (failure of $\mathrm{Wg}$ transport). Presynaptically, we find increased synaptic bouton number in cow null mutants phenocopying the Wg OE condition (Kopke et al., 2017), consistent with this hypothesis. These results indicate that Cow normally inhibits NMJ bouton formation, consistent with the effects of inhibiting presynaptic $\mathrm{Wg}$ 
signaling (Packard et al., 2002). Postsynaptically, we find an increased number of GluR clusters due to elevated synapse formation in cow null mutants, but no evidence of diffuse GluR clusters of irregular size/shape and larger volume, as has been reported in wg mutants (Packard et al., 2002; Speese et al., 2012; Kerr et al., 2014). Therefore, we do not find strong support for the second prediction of the hypothesis. GluR changes within single postsynaptic domains are challenging to see even with enhanced resolution microscopy (e.g., the SIM used here; Gustafsson, 2000), but future studies could focus more on GluRIIA cluster size/shape/intensity in cow mutants. If GluR defects are detected in cow nulls, it would be interesting to test the FNI pathway (Mathew et al., 2005).

Wg signaling regulates multiple steps of NMJ development including branching, satellite bouton budding, and synaptic bouton maturation (Koles and Budnik, 2012). None of the cow manipulations cause changes in branching, indicating that Cow does not regulate this Wg signaling, likely working in concert with other $\mathrm{Wg}$ regulators. $\mathrm{Wg}$ loss $\left(w g^{t s}\right.$ ) decreases bouton formation (Packard et al., 2002), while neural Wg OE increases branching, satellite, and total bouton numbers (Packard et al., 2002; Miech et al., 2008; Kopke et al., 2017). Satellite boutons represent an immature stage of development, with small boutons connected to the mature (parent) bouton or adjacent axon (Torroja et al., 1999; Gatto and Broadie, 2008). Neuronal Cow OE does not change mature bouton number, but increases satellite bouton budding. Neuronal Cow RNAi also increases satellite boutons. Thus, changing neural Cow levels in either direction elevates satellite bouton numbers, suggesting different consequences on budding versus developmental arrest. It also appears that the cellular source of secreted Cow, or the balance between sources, may be important for proper $\mathrm{Wg}$ regulation. Importantly, glia-secreted $\mathrm{Wg}$ regulates distinct aspects of synaptic development (Kerr et al., 2014), with loss of glial-derived Wg accounting for some, but not all, of $w g$ mutant phenotypes. Similarly, cell-targeted cow manipulations cause different NMJ phenotypes. There is no evidence for normal Cow function in postsynaptic muscle, but it remains possible that Cow secreted from glia could regulate $\mathrm{Wg}$ trans-synaptic signaling.

Increasing Wg signaling elevates evoked transmission strength and functional synapse number (Kopke et al., 2017), which is phenocopied in cow null mutants. Block of postsynaptic Wg signaling causes increased SV fusion frequency and amplitude of miniature excitatory junctional potentials (Speese et al., 2012). With neuronal cow RNAi, there is a similar increase in event frequency and amplitude. These results suggest a decrease in postsynaptic Wg signaling when cow is lost, supporting the Wg transport hypothesis. Blocking $\mathrm{Wg}$ secreted from neurons or glia increases muscle GluR cluster size, albeit with differential effects on neurotransmission efficacy (Kerr et al., 2014). Reducing neuronal Wg has no effect on mEJC frequency, but reducing glial-derived $\mathrm{Wg}$ increases SV fusion frequency (Kerr et al., 2014). Both nerve-evoked and spontaneous neurotransmission are increased in cow null mutants, together with increased Brp active zones and postsynaptic GluR clusters forming supernumerary synapses. SynapGCaMP is an exciting new tool to test function at individual synapses (Newman et al., 2017). With targeted neuronal cow RNAi, there is an increase in both the number of SV fusion events and the postsynaptic $\mathrm{Ca}^{2+}$ signal amplitude, which is consistent with both presynaptic and postsynaptic regulation of $\mathrm{Wg}$ signaling (Packard et al., 2002; Speese et al., 2012; Kerr et al., 2014). These functional phenotypes, combined with coordinated changes in presynaptic and postsynaptic formation suggest Cow regulates trans-synaptic $\mathrm{Wg}$ transport.

There were differences between spontaneous synaptic vesicle fusion findings between TEVC electrophysiological recordings and SynapGCaMP reporter (MHC-CD8GCaMP6f-Sh) $\mathrm{Ca}^{2+}$ imaging (Newman et al., 2017). Motor neurons that presynaptically targeted cow RNAi showed stronger impacts on SV fusion frequency with imaging in contrast to recordings, comparable to effects in the cow ${ }^{G D P}$ null mutants. Moreover, SynapGCaMP imaging revealed significantly larger SV fusion event magnitudes in contrast to the lack of change found with TEVC recording. While the basis of these differences in unknown, we speculate that it is due to the differential nature or sensitivity of these two methods. The $\mathrm{Ca}^{2+}$ imaging is based on measuring the change in the fluorescence signal over the baseline NMJ fluorescence $\left(\Delta F / F_{0}\right.$; Newman et al., 2017), and it may be that glutamate receptor $\mathrm{Ca}^{2+}$ permeability or intracellular $\mathrm{Ca}^{2+}$ signaling dynamics is changed in a way not directly related to detectable membrane current changes in the cow mutants. TEVC recordings capture whole NMJ activity, whereas with imaging we only captured type $1 b$ bouton activity normalized to area. In future studies, SynapGCaMP imaging can be used to map spatial changes in synapse function by assaying quantal activity separately in convergent type $1 \mathrm{~s}$ and $1 \mathrm{~b}$ motor neuron inputs and within discrete synaptic boutons (Newman et al., 2017). Moreover, differences between cow $^{G D P}$ and cow ${ }^{G D P} / D f$ conditions could be influenced by second site-enhancing mutations on the Df chromosome. Overall, it should be noted that the changes in spontaneous SV fusion frequency and amplitude in cow mutants are subtle and variable, and need to be further studied in the future.

$\mathrm{Wg}$ is lipid modified via palmitoylation to become strongly membrane associated (Zhai et al., 2004). The hydrophobic moiety is located at the interface of $\mathrm{Wg}$ and Fz2 binding, shielded from the aqueous environment by multiple extracellular transporters until signaling interaction with the receptor (Takada et al., 2017). There have been many modes of extracellular $\mathrm{Wg}$ transport demonstrated, primarily from work in the wing disk, including microvesicles, lipoproteins, exosomes, and cytoneme membrane extensions (Greco et al., 2001; Panáková et al., 2005; Gross et al., 2012; Huang and Kornberg, 2015). These multiple mechanisms of transport are much less studied at the synapse; however, exosome-like vesicles containing the Wg-binding protein Evenness Interrupted (Evi) have been demonstrated at the Drosophila NMJ (Korkut et al., 2009). Cow could be considered an alternative extracellular Wg transport method (Chang and Sun, 
2014), acting to shield $\mathrm{Wg}$ while facilitating transport through the extracellular synaptomatrix (Dani and Broadie, 2012; Dear et al., 2016). In addition, HSPGs have been shown to regulate ligands by stabilizing, degrading, or sequestering the ligand, or as bifunctional coreceptors, or as facilitators of transcytosis (Lin, 2004; Dani et al., 2012; Dear et al., 2017). Results presented here are consistent with the hypothesis that Cow is mediating $\mathrm{Wg}$ transport across the NMJ synapse (Chang and Sun, 2014), but also that Cow has an additional role in the negative regulation of $\mathrm{Wg}$ synaptic signaling.

The need for secreted $\mathrm{Wg}$ has been recently challenged, with $\mathrm{Wg}$ tethering to the membrane (NRT-wg) showing Wg secretion to be largely dispensable for development (Alexandre et al., 2014). In contrast, other recent studies suggest that $\mathrm{Wg}$ release and spreading is necessary (Beaven and Denholm, 2018; Pani and Goldstein, 2018; Stewart et al., 2019). We find tethering $\mathrm{Wg}$ at the NMJ synapse increases extracellular Wg ligand levels, with no change in mature bouton numbers. This $\mathrm{Wg}$ accumulation shows that NRT-wg is more stable at the synaptic signaling interface, consistent with other studies (Morata and Struhl, 2014; Chaudhary et al., 2019). However, although $\mathrm{Wg}$ levels increase, $\mathrm{Wg}$ signaling is less effective. With $N R T$-wg, only the budding of new satellite bouton is increased, with no increase in mature bouton formation. Reducing Wg function causes Fz2 upregulation (Cadigan et al., 1998; Chaudhary et al., 2019), so we hypothesize that Wg signaling could be maintained by increased presynaptic Fz2 receptors. When Wg is tethered, Cow cannot mediate intercellular transport, so the hypothesis predicts a similar phenotype with Cow (NRT-wg) or without Cow (NRT-wg; cow ${ }^{G D P}$ ). Indeed, Cow removal in the NRT-wg condition does not impact synaptic bouton number, although it does block the increase in satellite boutons, consistent with a Cow role in greater Wg stability (Chang and Sun, 2014). These results show that Wg secretion is required for the elevated NMJ development characterizing cow mutant animals.

To further test how Cow is working through the $\mathrm{Wg}$ pathway to negatively regulate NMJ development, we turned to genetic interaction tests with the Wg-negative regulator Notum (Gerlitz and Basler, 2002; Giráldez et al., 2002; Kakugawa et al., 2015). At the NMJ, Wg trans-synaptic signaling is elevated in the absence of Notum, and null notum mutants display larger NMJs with more synaptic boutons, increased synapse number and elevated neurotransmission (Kopke et al., 2017). All these defects are phenocopied by neuronal Wg OE, showing that the positive synaptogenic phenotypes arise from lack of $\mathrm{Wg}$ signaling inhibition. Consistently, genetically correcting $\mathrm{Wg}$ levels at the synapse in notum nulls alleviates synaptogenic phenotypes (Kopke et al., 2017). We show here that cow null mutants have the same phenotypes of expanded NMJs, supernumerary synaptic boutons, greater synapse number/function, and strengthened transmission, suggesting that Cow acts like Notum in regulating Wg signaling. We performed a genetic test to ask whether Cow and Notum work in this same pathway. While cow and notum null heterozygotes do not exhibit NMJ defects, cow/ notum trans-heterozygotes display grossly expanded NMJs with excess boutons. This combined haplo-insufficiency (type 3 SSNC) of nonallelic noncomplementation suggests that Cow and Notum share related roles (Yook et al., 2001; Hawley and Gilliland, 2006). When we tested full double mutants, there is no additive effect, showing that Cow and Notum restrict $\mathrm{Wg}$ signaling in the same pathway. However, this pathway convergence appears restricted only to the control of structural synaptogenesis but not of functional neurotransmission, although the control neurotransmission amplitude was elevated in these studies.

Cow now joins the list of synaptic HSPGs with key roles in NMJ development. HSPGs have been implicated in vertebrate NMJ synapse formation for $>3$ decades (Kamimura and Maeda, 2017; Condomitti and de Wit, 2018). The Agrin HSPG is secreted from presynaptic terminals to maintain postsynaptic acetylcholine receptor clustering (Godfrey et al., 1984; Hubbard and Gnanasambandan, 2013). Another secreted HSPG, perlecan, regulates acetylcholinesterase localization (Peng et al., 1999; Arikawa-Hirasawa et al., 2002). Drosophila NMJ analyses have begun to more systematically elucidate HSPG roles in NMJ formation and function (Ren et al., 2009; Kamimura and Maeda, 2017). In particular, the glypican HSPG Dlp regulates Wg signaling to modulate both NMJ structure and function, including the regulation of active zone formation and SV release (Johnson et al., 2006; Dani et al., 2012; Friedman et al., 2013; Dear et al., 2017). Wg binds the core Dlp, with HS chains enhancing this binding, to retain $\mathrm{Wg}$ on the cell surface, where it can both compete with Fz2 receptors and facilitate $\mathrm{Wg}-\mathrm{Fz} 2$ binding (Yan et al., 2009). This biphasic activity depends on the ratio of Wg, Fz2, and Dlp HSPG as expounded in the "exchange factor model" (Yan et al., 2009; Dear et al., 2016). Cow may impact this exchange factor mechanism as a fourth player, acting with Dlp to modulate Wg transport and Wg-Fz2 binding at the synaptic interface. It will be important to test Dlp levels and distribution in cow nulls to see how Cow fits into this model.

In addition to Cow, perlecan (Trol) is another secreted HSPG reported to regulate bidirectional Wg signaling at the Drosophila NMJ (Kamimura et al., 2013). Trol has been localized near the muscle membrane, where it promotes postsynaptic $\mathrm{Wg}$ accumulation. In the absence of Trol, Wg builds up presynaptically, causing excess satellite bouton formation (Kamimura et al., 2013). It is interesting to note that cow mutants enhance $\mathrm{Wg}$ signaling without increasing satellite boutons. In trol mutants, ghost boutons increase due to decreased postsynaptic Wg signaling (Kamimura et al., 2013). Note that cow mutants do not exhibit ghost boutons, which fails to support decreased postsynaptic Wg signaling. Other postsynaptic defects in trol mutants (e.g., reduced SSR, increased postsynaptic pockets; Kamimura et al., 2013) are NMJ ultrastructural features that could be a future focus using electron microscopy studies. Similar to cow mutants, extracellular Wg levels are decreased in the absence of Trol, speculated due to increased $\mathrm{Wg}$ proteolysis, since HS protects HS-binding proteins from degradation (Saksela et al., 1988). In cow mutants, it is not yet known whether 
$\mathrm{Wg}$ is decreased due to elevated signaling (ligand/receptor endocytosis) or to increased degradation due to Cow no longer protecting/stabilizing the ligand. Given that synaptic Fz2 is internalized with Wg binding (Mathew et al., 2005), future experiments could test internalized Fz2 levels in cow mutants as a proxy of $\mathrm{Wg}$ signaling.

In summary, we have confirmed here new tools to study Cow HSPG function, and have discovered that Cow from presynaptic motor neurons restricts NMJ bouton formation, glutamatergic synapse number, and NMJ functional differentiation. Cow acts within the same Wg trans-synaptic signaling pathway as Notum by regulating the Wg ligand in the extracellular synaptomatrix. Secreted Cow modulates extracellular Wg ligand levels, with additional functions controlling $\mathrm{Wg}$ signaling efficacy, which may be independent of or dependent on Wg transport. It will be interesting to determine whether Cow core protein and/or its HS chains are important for the synaptic structural and functional phenotypes. Wg must be secreted for Cow to act on it, as shown by the membrane-tethered interaction studies, showing that secreted Cow must work on the freely diffusible $\mathrm{Wg}$ ligand. Perhaps most informative for our future studies will be dissection of the interactions, coordination or redundancy of the multiple synaptic HSPGs at the NMJ, to further the understanding of extracellular Wg trans-synaptic signaling regulation during synaptic development. Drosophila is a particularly well suited model to study HSPGs because of the relatively reduced complexity in this system (17 HSPGs in mammals vs 5 HSPGs in Drosophila; Sarrazin et al., 2011). We look forward to expanding future studies to examine multiple synaptic HSPGs in parallel, with the goal of elucidating the surprisingly complex control of trans-synaptic signaling occurring within the extracellular synaptomatrix.

\section{References}

Alexandre C, Baena-Lopez A, Vincent J-P (2014) Patterning and growth control by membrane-tethered Wingless. Nature 505:180185.

Arikawa-Hirasawa E, Rossi SG, Rotundo RL, Yamada Y (2002) Absence of acetylcholinesterase at the neuromuscular junctions of perlecan-null mice. Nat Neurosci 5:119-123.

Ataman B, Ashley J, Gorczyca D, Gorczyca M, Mathew D, Wichmann C, Sigrist SJ, Budnik V (2006) Nuclear trafficking of Drosophila Frizzled-2 during synapse development requires the PDZ protein dGRIP. Proc Natl Acad Sci U S A 103:7841-7846.

Ataman B, Ashley J, Gorczyca M, Ramachandran P, Fouquet W, Sigrist SJ, Budnik V (2008) Rapid activity-dependent modifications in synaptic structure and function require bidirectional Wnt signaling. Neuron 57:705-718.

Baeg GH, Lin X, Khare N, Baumgartner S, Perrimon N (2001) Heparan sulfate proteoglycans are critical for the organization of the extracellular distribution of Wingless. Development 128:87-94.

Beaven R, Denholm B (2018) Release and spread of Wingless is required to pattern the proximo-distal axis of Drosophila renal tubules. Elife 7:e35373.

Bellen HJ, Levis RW, Liao G, He Y, Carlson JW, Tsang G, EvansHolm M, Hiesinger PR, Schulze KL, Rubin GM, Hoskins RA, Spradling AC (2004) The BDGP Gene Disruption Project: Single transposon insertions associated with $40 \%$ of Drosophila genes. Genetics 167:761-781.

Bhanot P, Brink M, Samos CH, Hsieh J-C, Wang Y, Macke JP, Andrew D, Nathans J, Nusse R (1996) A new member of the frizzled family from Drosophila functions as a Wingless receptor. Nature 382:225-230.

Cadigan KM, Fish MP, Rulifson EJ, Nusse R (1998) Wingless repression of Drosophila frizzled 2 expression shapes the wingless morphogen gradient in the wing. Cell 93:767-777.

Chang Y-H, Sun YH (2014) Carrier of Wingless (Cow), a secreted heparan sulfate proteoglycan, promotes extracellular transport of Wingless. PLoS One 9:e111573.

Chaudhary V, Hingole S, Frei J, Port F, Strutt D, Boutros M (2019) Robust Wnt signaling is maintained by a $\mathrm{Wg}$ protein gradient and Fz2 receptor activity in the developing Drosophila wing. Development 146:dev174789.

Condomitti G, de Wit J (2018) Heparan sulfate proteoglycans as emerging players in synaptic specificity. Front Mol Neurosci 11:14.

Dani N, Broadie K (2012) Glycosylated synaptomatrix regulation of trans-synaptic signaling. Dev Neurobiol 72:2-21.

Dani N, Nahm M, Lee S, Broadie K (2012) A targeted glycan-related gene screen reveals heparan sulfate proteoglycan sulfation regulates WNT and BMP trans-synaptic signaling. PLoS Genet 8: e1003031.

Dear ML, Dani N, Parkinson W, Zhou S, Broadie K (2016) Two classes of matrix metalloproteinases reciprocally regulate synaptogenesis. Development 143:75-87.

Dear ML, Shilts J, Broadie K (2017) Neuronal activity drives FMRPand HSPG-dependent matrix metalloproteinase function required for rapid synaptogenesis. Sci Signal 10:eaan3181.

Franco B, Bogdanik L, Bobinnec Y, Debec A, Bockaert J, Parmentier M-L, Grau Y (2004) Shaggy, the homolog of glycogen synthase kinase 3, controls neuromuscular junction growth in Drosophila. J Neurosci 24:6573-6577.

Friedman S, Dani N, Rushton E, Broadie K (2013) Fragile X mental retardation protein regulates trans-synaptic signaling in Drosophila. Dis Model Mech 6:1400-1413.

Gatto CL, Broadie K (2008) Temporal requirements of the fragile $X$ mental retardation protein in the regulation of synaptic structure. Development 135:2637-2648.

Gerlitz O, Basler K (2002) Wingful, an extracellular feedback inhibitor of Wingless. Genes Dev 16:1055-1059.

Giráldez AJ, Copley RR, Cohen SM (2002) HSPG modification by the secreted enzyme notum shapes the Wingless morphogen gradient. Dev Cell 2:667-676.

Godfrey EW, Nitkin RM, Wallace BG, Rubin LL, McMahan UJ (1984) Components of Torpedo electric organ and muscle that cause aggregation of acetylcholine receptors on cultured muscle cells. J Cell Biol 99:615-627.

Graf ER, Daniels RW, Burgess RW, Schwarz TL, DiAntonio A (2009) Rab3 dynamically controls protein composition at active zones. Neuron 64:663-677.

Greco V, Hannus M, Eaton S (2001) Argosomes: A potential vehicle for the spread of morphogens through epithelia. Cell 106:633-645.

Gross JC, Chaudhary V, Bartscherer K, Boutros M (2012) Active Wnt proteins are secreted on exosomes. Nat Cell Biol 14:1036-1045.

Gustafsson MGL (2000) Surpassing the lateral resolution limit by a factor of two using structured illumination microscopy. J Microsc 198:82-87.

Hallermann S, Kittel RJ, Wichmann C, Weyhersmüller A, Fouquet W, Mertel S, Owald D, Eimer S, Depner H, Schwärzel M, Sigrist SJ, Heckmann M (2010) Naked dense bodies provoke depression. J Neurosci 30:14340-14345.

Han C, Yan D, Belenkaya TY, Lin X (2005) Drosophila glypicans Dally and Dally-like shape the extracellular Wingless morphogen gradient in the wing disc. Development 132:667-679.

Hawley RS, Gilliland WD (2006) Sometimes the result is not the answer: The truths and the lies that come from using the complementation test. Genetics 174:5-15.

Huang H, Kornberg TB (2015) Myoblast cytonemes mediate Wg signaling from the wing imaginal disc and Delta-Notch signaling to the air sac primordium. Elife 4:e06114. 
Hubbard SR, Gnanasambandan K (2013) Structure and activation of MuSK, a receptor tyrosine kinase central to neuromuscular junction formation. Biochim Biophys Acta 1834:2166-2169.

Jan LY, Jan YN (1982) Antibodies to horseradish peroxidase as specific neuronal markers in Drosophila and in grasshopper embryos. Proc Natl Acad Sci U S A 79:2700-2704.

Johnson KG, Tenney AP, Ghose A, Duckworth AM, Higashi ME, Parfitt K, Marcu O, Heslip TR, Marsh JL, Schwarz TL, Flanagan JG, Van Vactor D (2006) The HSPGs Syndecan and Dallylike bind the receptor phosphatase LAR and exert distinct effects on synaptic development. Neuron 49:517-531.

Kakugawa S, Langton PF, Zebisch M, Howell S, Chang T-H, Liu Y, Feizi T, Bineva G, O'Reilly N, Snijders AP, Jones EY, Vincent J-P (2015) Notum deacylates Wnt proteins to suppress signalling activity. Nature 519:187-192.

Kamimura K, Ueno K, Nakagawa J, Hamada R, Saitoe M, Maeda N (2013) Perlecan regulates bidirectional Wnt signaling at the Drosophila neuromuscular junction. J Cell Biol 200:219-233.

Kamimura K, Maeda N (2017) Heparan sulfate proteoglycans in Drosophila neuromuscular development. Biochim Biophys Acta Gen Subj 1861:2442-2446.

Kerr KS, Fuentes-Medel Y, Brewer C, Barria R, Ashley J, Abruzzi KC, Sheehan A, Tasdemir-Yilmaz OE, Freeman MR, Budnik V (2014) Glial Wingless/Wnt regulates glutamate receptor clustering and synaptic physiology at the Drosophila neuromuscular junction. J Neurosci 34:2910-2920.

Kittel RJ, Wichmann C, Rasse TM, Fouquet W, Schmidt M, Schmid A, Wagh DA, Pawlu C, Kellner RR, Willig KI, Hell SW, Buchner E, Heckmann M, Sigrist SJ (2006) Bruchpilot promotes active zone assembly, $\mathrm{Ca}^{2+}$ channel clustering, and vesicle release. Science 312:1051-1054.

Koles K, Budnik V (2012) Wnt signaling in neuromuscular junction development. Cold Spring Harb Perspect Biol 4:a008045.

Kopke DL, Lima SC, Alexandre C, Broadie K (2017) Notum coordinates synapse development via extracellular regulation of Wingless trans-synaptic signaling. Development 144:3499-3510.

Korkut C, Ataman B, Ramachandran P, Ashley J, Barria R, Gherbesi N, Budnik V (2009) Trans-synaptic transmission of vesicular Wnt signals through Evi/Wntless. Cell 139:393-404.

Lahey T, Gorczyca M, Jia X-X, Budnik V (1994) The Drosophila tumor suppressor gene dlg is required for normal synaptic bouton structure. Neuron 13:823-835.

Lin X (2004) Functions of heparan sulfate proteoglycans in cell signaling during development. Development 131:6009-6021.

Marrus SB, Portman SL, Allen MJ, Moffat KG, DiAntonio A (2004) Differential localization of glutamate receptor subunits at the Drosophila neuromuscular junction. J Neurosci 24:1406-1415.

Masu M (2016) Proteoglycans and axon guidance: A new relationship between old partners. J Neurochem 139:58-75.

Mathew D, Ataman B, Chen J, Zhang Y, Cumberledge S, Budnik V (2005) Wingless signaling at synapses is through cleavage and nuclear import of receptor DFrizzled2. Science 310:1344-1347.

Menon KP, Carrillo RA, Zinn K (2013) Development and plasticity of the Drosophila larval neuromuscular junction. Wiley Interdiscip Rev Dev Biol 2:647-670.

Miech C, Pauer H-U, He X, Schwarz TL (2008) Presynaptic local signaling by a canonical Wingless pathway regulates development of the Drosophila neuromuscular junction. J Neurosci 28:1087510884.

Morata G, Struhl G (2014) Tethered wings. Nature 505:162-163.

Nagarkar-Jaiswal S, Lee P-T, Campbell ME, Chen K, AnguianoZarate S, Cantu Gutierrez M, Busby T, Lin W-W, He Y, Schulze KL, Booth BW, Evans-Holm M, Venken KJ, Levis RW, Spradling AC, Hoskins RA, Bellen HJ (2015) A library of MiMICs allows tagging of genes and reversible, spatial and temporal knockdown of proteins in Drosophila. Elife 4:e05338.

Neumann CJ, Cohen SM (1997) Long-range action of Wingless organizes the dorsal-ventral axis of the Drosophila wing. Development 124:871-880.
Newman ZL, Hoagland A, Aghi K, Worden K, Levy SL, Son JH, Lee LP, Isacoff EY (2017) Input-specific plasticity and homeostasis at the Drosophila larval neuromuscular junction. Neuron 93:1388-1404.

Packard M, Koo ES, Gorczyca M, Sharpe J, Cumberledge S, Budnik V (2002) The Drosophila Wnt, wingless, provides an essential signal for pre- and postsynaptic differentiation. Cell 111:319-330.

Panáková D, Sprong H, Marois E, Thiele C, Eaton S (2005) Lipoprotein particles are required for Hedgehog and Wingless signalling. Nature 435:58-65.

Pani AM, Goldstein B (2018) Direct visualization of a native Wnt in vivo reveals that a long-range Wnt gradient forms by extracellular dispersal. Elife 7:e38325.

Parkinson W, Dear ML, Rushton E, Broadie K (2013) N-glycosylation requirements in neuromuscular synaptogenesis. Development 140:4970-4981.

Parkinson WM, Dookwah M, Dear ML, Gatto CL, Aoki K, Tiemeyer M, Broadie K (2016) Synaptic roles for phosphomannomutase type 2 in a new Drosophila congenital disorder of glycosylation disease model. Dis Model Mech 9:513-527.

Parnas D, Haghighi AP, Fetter RD, Kim SW, Goodman CS (2001) Regulation of postsynaptic structure and protein localization by the Rho-type guanine nucleotide exchange factor dPix. Neuron 32:415-424.

Peng HB, Xie H, Rossi SG, Rotundo RL (1999) Acetylcholinesterase clustering at the neuromuscular junction involves perlecan and dystroglycan. J Cell Biol 145:911-921.

Ren Y, Kirkpatrick CA, Rawson JM, Sun M, Selleck SB (2009) Cell type-specific requirements for heparan sulfate biosynthesis at the Drosophila neuromuscular junction: Effects on synapse function, membrane trafficking, and mitochondrial localization. J Neurosci 29:8539-8550.

Saksela O, Moscatelli D, Sommer A, Rifkin DB (1988) Endothelial cellderived heparan sulfate binds basic fibroblast growth factor and protects it from proteolytic degradation. J Cell Biol 107:743-751.

Sarrazin S, Lamanna WC, Esko JD (2011) Heparan sulfate proteoglycans. Cold Spring Harb Perspect Biol 3:a004952.

Schnepp A, Lindgren PK, Hülsmann $H$, Kröger S, Paulsson $M$, Hartmann U (2005) Mouse testican-2 expression, glycosylation and effects on neurite outgrowth. J Biol Chem 280:11274-11280.

Schuster CM, Ultsch A, Schloss P, Cox JA, Schmitt B, Betz H (1991) Molecular cloning of an invertebrate glutamate receptor subunit expressed in Drosophila muscle. Science 254:112-114.

Sears JC, Broadie K (2018) Fraile X Mental Retardation Protein regulates activity-dependent membrane trafficking and trans-synaptic signaling mediated synaptic remodeling. Front Mol Neurosci 10:440.

Shilts J, Broadie K (2017) Secreted tissue inhibitor of matrix metalloproteinase restricts trans-synaptic signaling to coordinate synaptogenesis. J Cell Sci 130:2344-2358.

Speese SD, Ashley J, Jokhi V, Nunnari J, Barria R, Li Y, Ataman B, Koon A, Chang Y-T, Li Q, Moore MJ, Budnik V (2012) Nuclear envelope budding enables large ribonucleoprotein particle export during synaptic Wnt signaling. Cell 149:832-846.

Stewart RA, Ramakrishnan A-B, Cadigan KM (2019) Diffusion and function of Wnt ligands. PLoS Genet 15:e1008154.

Takada S, Fujimori S, Shinozuka T, Takada R, Mii Y (2017) Differences in the secretion and transport of Wnt proteins. $J$ Biochem 161:1-7.

Torroja L, Packard M, Gorczyca M, White K, Budnik V (1999) The Drosophila $\beta$-amyloid precursor protein homolog promotes synapse differentiation at the neuromuscular junction. J Neurosci 19:7793-7803.

Tsuda M, Kamimura K, Nakato H, Archer M, Staatz W, Fox B, Humphrey M, Olson S, Futch T, Kaluza V, Siegfried E, Stam L, Selleck SB (1999) The cell-surface proteoglycan Dally regulates Wingless signalling in Drosophila. Nature 400:276-280.

Vannahme $C$, Schübel $S$, Herud $M$, Gösling $S$, Hülsmann $H$, Paulsson M, Hartmann U, Maurer P (1999) Molecular cloning of testican-2: Defining a novel calcium-binding proteoglycan family expressed in brain. J Neurochem 73:12-20. 
Wagh DA, Rasse TM, Asan E, Hofbauer A, Schwenkert I, Dürrbeck H, Buchner S, Dabauvalle M-C, Schmidt M, Qin G, Wichmann C, Kittel R, Sigrist S, Buchner E (2006) Bruchpilot, a protein with homology to ELKS/CAST, is required for structural integrity and function of synaptic active zones in Drosophila. Neuron 49:833844.

Yan D, Wu Y, Feng Y, Lin S-C, Lin X (2009) The core protein of glypican Dally-like determines its biphasic activity in Wingless morphogen signaling. Dev Cell 17:470-481.
Yook KJ, Proulx SR, Jorgensen EM (2001) Rules of nonallelic noncomplementation at the synapse in Caenorhabditis elegans. Genetics 158:209-220.

Zecca M, Basler K, Struhl G (1996) Direct and long-range action of a Wingless morphogen gradient. Cell 87:833-844.

Zhai L, Chaturvedi D, Cumberledge S (2004) Drosophila Wnt-1 undergoes a hydrophobic modification and is targeted to lipid rafts, a process that requires porcupine. J Biol Chem 279:3322033227. 